\title{
New Developments in Liquid Chromatography Mass Spectrometry for the Determination of Micropollutants
}

\author{
Zoraida Sosa-Ferrera, Cristina Mahugo-Santana, and José Juan Santana-Rodríguez \\ Departamento de Química, Universidad de Las Palmas de Gran Canaria, 35017 Las Palmas de Gran Canaria, Spain \\ Correspondence should be addressed to José Juan Santana-Rodríguez, jsantana@dqui.ulpgc.es
}

Received 7 October 2012; Accepted 13 November 2012

Academic Editor: Toyohide Takeuchi

Copyright () 2012 Zoraida Sosa-Ferrera et al. This is an open access article distributed under the Creative Commons Attribution License, which permits unrestricted use, distribution, and reproduction in any medium, provided the original work is properly cited.

\begin{abstract}
The combination of liquid chromatography (LC) with mass spectrometry (MS) in the environmental field has appeared as a valuable tool for the determination of micropollutants. Several groups of compounds have been considered as particularly relevant (e.g., pharmaceuticals, hormones and other endocrine-disrupting, personal care products and their metabolites, flame retardants, surfactants, and plasticizers, among others) since the same ones are continuously being released in the environment mainly as a result of the manufacturing processes, the disposal of unused or expired products, and the excreta. Because these micropollutants are not completely removed in the environment, very specific and sensitive analytical procedures are needed for their identification and quantification. High performance liquid chromatography coupled to tandem mass spectrometry (LC-MS/MS) (or LC-MS ${ }^{2}$ ) and especially time-of-flight mass spectrometry (TOF/MS), has allowed that many environmental contaminants that are highly polar or nonvolatile or have a high molecular weight to be analyzed or identified. In this work we present an overview focused on the developments of liquid chromatography mass spectrometry applied to the analysis of the main classes of micropollutants in aqueous and solid environmental samples. Various aspects of methodologies based on these techniques, including sample preparation (extraction/preconcentration) and matrix effects, are discussed.
\end{abstract}

\section{Introduction}

Over the last two decades the use of LC techniques coupling with a high resolution MS to identify unknown contaminants has advanced spectacularly. This progress is mostly due to the development of new instrumentation. LC techniques have replaced gas chromatography (GC) as they present obvious advantages such as reduced sample pretreatment and their capacity to determine polar or thermally stabile compounds.

The combination of LC and MS offers the possibility to take advantages of both LC as a powerful and versatile separation technique and MS as a powerful and sensitive detection and identification technique. The intrinsic properties of these two techniques result in an extremely analytical tool useful with many application areas. There are many different LC-MS systems on the market, that present advantages and limitations according to the type of samples that must be analyzed.
Interface designs have changed considerably and have become much more sophisticated and efficient. Since the introduction of atmospheric pressure ionization techniques (API), LC-MS has played an increasingly important role in environmental analysis allowing to analyze a broad range of compounds, including nonvolatile, thermally labile, and polar species. Today, the interfaces most widely used for the LC-MS analysis are electrospray (ESI) and atmospheric pressure chemical ionisation (APCI), both using atmospheric pressure ionization (API). They produce protonated $[\mathrm{M}+\mathrm{H}]^{+}$or deprotonated $[\mathrm{M}-\mathrm{H}]^{-}$molecules. ESI is particularly well suited for the analysis of polar compounds whereas APCI is highly effective in the analysis of mediumand low-polarity substances. When ESI is operating in the negative ion mode of ionisation (NI) the sensitivity achieved in the analysis of some relevant pollutant compounds is considerably better than that of the ESI interface operating in the positive ion mode of ionisation (PI) and the APCI interface operating in the NI mode $[1,2]$. However, some recent 
studies [3-5] indicate that the APCI interface operating in the PI mode can furnish sensitivities comparable in many cases to that of the negative ion ESI.

Combined ion sources can be considered as an option merging the advantages and application ranges of atmospheric pressure ionization techniques, but on the other hand their sensitivity may be a compromise between both modes. The advantage of combined ESI/APCI [6] ion sources is the possible detection of both polar and nonpolar analytes in one run, which can increase the number of the identified components for highly complex matrices.

These API technologies have been interfaced with a variety of mass analysers, including single-(Q) and triplequadrupole (QqQ), orthogonal-acceleration time-of-flight (oaTOF), linear ion trap (LIT), and sector-field MS instruments.

For complex samples, containing many compounds, LC-MS is not enough for the unequivocal confirmation of analytes for the final identification. LC-MS ${ }^{2}$ takes out this problem and results in a much higher degree of certainty in the identification of the unknowns. Triplequadrupole $(\mathrm{QqQ})$ mass analyzers have become the most widely used analytical tool in the environmental analysis. Their application has allowed the determination of a great number of compounds, especially polar ones that were previously difficult or even impossible to analyze. More recent approaches in LC-MS ${ }^{2}$ are linear ion traps (LITs), new-generation QqQs, and hybrid instruments, such as quadrupole time-of-flight (Qq-TOF) and Q-linear ion traps (Qq-LITs). When the first quadrupole of a QqQ is replaced by a double-focusing mass spectrometer, the instrument is termed a hybrid. Hybrid Qq-TOF-MS technique is the most common application in the structural characterization in the environmental analysis and allows an unequivocal confirmation of the contaminants detected. Moreover, TOF-based mass analyzers allow to find additional nontarget organic contaminants. The elimination of false positives is possible by generating full-scan production spectra with an exact mass. Qq-LIT is considered as a very powerful tool for a rapid identification and confirmation of metabolites in different matrices because of its capability of producing additional spectral information useful for structure clarification [7-9].

Some papers compared a real performance of different types of modern tandem mass analyzers for particular applications, which provides valuable complementary information. LC-MS with QqQ and LIT has been compared for the determination of 6 pesticides in fruits [10]. QqQ provides better linear dynamic range, higher precision, less matrix interferences, and better robustness, while LIT provides an excellent sensitivity for product ion measurements. Four LC-MS systems equipped with Q, QqQ, IT (ion trap) and Q-TOF have been compared in the quantitative analysis (sensitivity, precision, and accuracy) of carbosulfan and its main transformation products [11]. QqQ provides at least 20-fold higher sensitivity compared to other mass analyzers and better linear dynamic range. The repeatability (within a day) is slightly better for Q (5-10\%) and QqQ (5-9\%) compared to LIT (12-16\%) and Q-TOF (9-16\%). Although the QqQ is more sensitive and precise, mean values obtained by all instruments are comparable.

The miniaturization is an important issue considered in all fields of analytical instrumentation including both parts of LC-MS coupling. The most widespread and wellestablished approach is UHPLC [12], which is based on the use of small particle size (sub- $2 \mu \mathrm{m}$ particles) in the stationary phase and short columns, at ultrahigh pressures (up to 1300 bars) yielding fast analyses and narrow chromatographic peaks. Moreover, UHPLC dramatically shortens analysis times, often to $10 \mathrm{~min}$ or less $[13,14]$. On the other hand, it requires a higher acquisition speed of mass spectrometer to obtain enough sampling points for the reliable peak integration. Typical peak widths in routine LCMS are 3-10 s [14-16], while peak widths in the fast/ultrafast UHPLC-MS are generally in the range $1-3 \mathrm{~s}$, but they can be narrower than $1 \mathrm{~s}$ under well-optimized conditions [17, 18]. Modern TOF-based mass analyzers and also some ion traps are capable of reaching higher acquisition speed points for peak, what is useful to generate more sampling points per peak for a better quantification. Examples of potential applications of these methods have been published. Ibáñez et al. published an overview of the applications of UHPLC with TOF-MS for the rapid screening of multiclass organic pollutants in water [19].

The composition of the mobile phase is an important factor for improving separation in LC. An acidic condition with acetonitrile-water and methanol-water mixtures with a gradient elution is among the most common approach for improved peak shape in chromatography. Modification of the mobile phase, when performed in an attempt to improve the sensitivity of MS detection, has been accomplished with acetic acid, formic acid, or ammonium acetate. Nonvolatile additives, such as oxalic acid, should be avoided when ESI is used and trifluoroacetic (TFA) acid can suppress the ionization in the electrospray source.

The ion suppression/enhancement effects play an important role in LC-MS quantification and extend of these effects needs to be quantitatively assessed. The ion suppression and matrix effects can cause severe problems with the quantification in the trace analysis.

In MS quantification, to eliminate any possible variations during the ionization process and the mass analysis, such as the ion suppression/enhancement, the contamination of the ion source or the mobile phase, extraction losses, or any other unpredictable reasons, an internal standard must be used.

Another important issue is the sample preparation prior to LC-MS analysis [20]. Obviously, the internal standard must be added before any sample preconcentration step. Another alternative approach for the relative quantification is the use of response factors determined from the calibration curves of pure standards and then applied for real samples $[21,22]$. The internal standard addition and response factors approach can be combined in one platform together with the well-optimized chromatographic separation.

An overview of the applications of LC techniques coupled to mass spectrometry in the determination of the main classes of micropollutants in aqueous and solid environmental samples is presented. These compounds are present 
to very low concentrations and due to the high complexity of some environmental samples; very specific and sensitive analytical procedures are needed for their determination. Although these compounds are not currently covered by the existing regulations, the possibility of adverse effects on humans and animals and their extensive environmental distribution has recently attracted an increasing interest. In particular, these compounds include pharmaceuticals, personal care products, flame retardants, surfactants, and plasticizers, among others. Figure 1 shows a scheme summary of the micropollutants considered in this work.

Micropollutants contaminants are released into environment mainly as a result of the manufacturing processes, the disposal of unused or expired products, and the excreta, mostly through urban wastewater and many of them can further spread through the water cycle, even reaching drinking water, due to their hydrophilic character and low removal at wastewater treatment plants (WWTPs) and drinking water treatment plants (DWTPs) [23-25]. They can also enter into the environment due to surface-water runoffs and soil leaching after the agricultural applications of manure. Once released into the environment, micropollutants are subject to different processes, such as biodegradation and chemical and photochemical degradation, which contribute to their elimination. When these transformations take place, degradation products can differ in the environmental behaviour and toxicity. However, they are often more persistent than their corresponding parent compounds [26].

To obtain high recoveries and minimise interference, the determination of these pollutants requires extraction and clean-up steps prior to detection. Solid phase extraction (SPE) is frequently used to extract these compounds from aqueous samples [27]. However, the demand to reduce the solvent volumes and avoid the use of toxic organic solvents has led to substantial efforts to adapt existing sample preparation methods to the development of new approaches. Miniaturisation has been a key factor in the search of these objectives. Microextraction techniques allow high enrichment factors and minimise solvent consumption which avoid environmental pollution. Among these techniques are solid phase microextraction (SPME), stir-bar sorptive extraction (SBSE), and liquid-phase microextraction (LPME) approaches. Although SPME has been the technique most widely used, in recent years LPME approaches, such as single-drop microextraction (SDME), hollow-fiber liquid-phase microextraction (HF-LPME), and dispersive liquid-liquid microextraction (DLLME), have been growing more interest. The extraction of emerging pollutants from solid matrices is carried out by accelerated solvent extraction (ASE) pressurised liquid extraction (PLE), ultrasound assisted extraction (UAE), and microwave-assisted extraction (MAE). These methods have been replaced to Soxhlet extraction, the classical procedure for solid matrices [28-30].

The US Environmental Protection Agency (USEPA) published the final Contaminant Candidate List (CCL-3) in September 2009, which is a drinking water priority contaminant list for regulatory decision making and information collection. The listed contaminants are either known or anticipated to exist in drinking water systems and will be considered for a potential regulation. This final CCL3 contains 104 chemicals and 12 microbial contaminants, and it includes three pharmaceuticals, eight hormones, and several disinfectant by-products and industrial additives [31]. In the European Union (EU), the Water Framework Directive (WFD) sets the strategy against the pollution of water by dangerous substances. The WFD provisions will be required from Member States and Associated States to establish programs to monitor the quality of water, which implies a review of human activity on the pollutants and an economic analysis of water use. In this context, there is an urgent need for a list of emerging contaminants as possible candidates for introduction into the WFD list of priority substances. This can be amended every four years with revisions and additions of new contaminants [32].

\section{Application to the Determination of Micropollutants in Environmental Samples}

2.1. Pharmaceuticals Compounds. Among new contaminants, pharmaceuticals belong to a group of an increasing interest due to their pharmacological activity and rising consumption deriving from their use in human and veterinary medicine $[33,34]$. Moreover, due to their ubiquitous presence in the environment arising from continual input into the aquatic compartment, they are considered as "pseudo" persistent pollutants [35]. The discharge of therapeutic agents in effluents from production facilities, hospitals and private households, improper disposal of unused drugs, and the direct discharge of veterinary medicines leads to the contamination of environmental waters, and wastewatertreatment plants are considered to be a major source [33, 34, 36-38]. Biological treatment in WWTPs affects only the partial removal of a wide range of microcontaminants, especially polar ones, which are discharged into the final effluent. Thus, it has become evident that the application of more enhanced technologies may be crucial to full the requirements to recycle municipal and industrial wastewaters as drinking water. However, the removal of polar contaminants during drinking water treatment is incomplete. This fact was demonstrated by Ternes et al. when they investigated the elimination of selected pharmaceuticals, such as clofibric acid, bezafibrate, or carbamazepine, during drinking water treatment at the pilot-plant scale and in real waterworks in Germany [39]. The concentration of pharmaceuticals in water can vary between a few nanograms per liter to the micrograms per liter levels. These levels have to be removed in order to achieve the drinking water quality and to protect the water resources. Therefore, the concentrations and identities of these contaminants in water have to be monitored during the entire water purification and transportation process.

Antibiotics, followed by steroid compounds, analgesics, and nonsteroidal anti-inflammatory drugs (NSAIDs), are the most widely studied pharmaceuticals. Table 1 shows the diverse determinations of these compounds in environmental samples. 


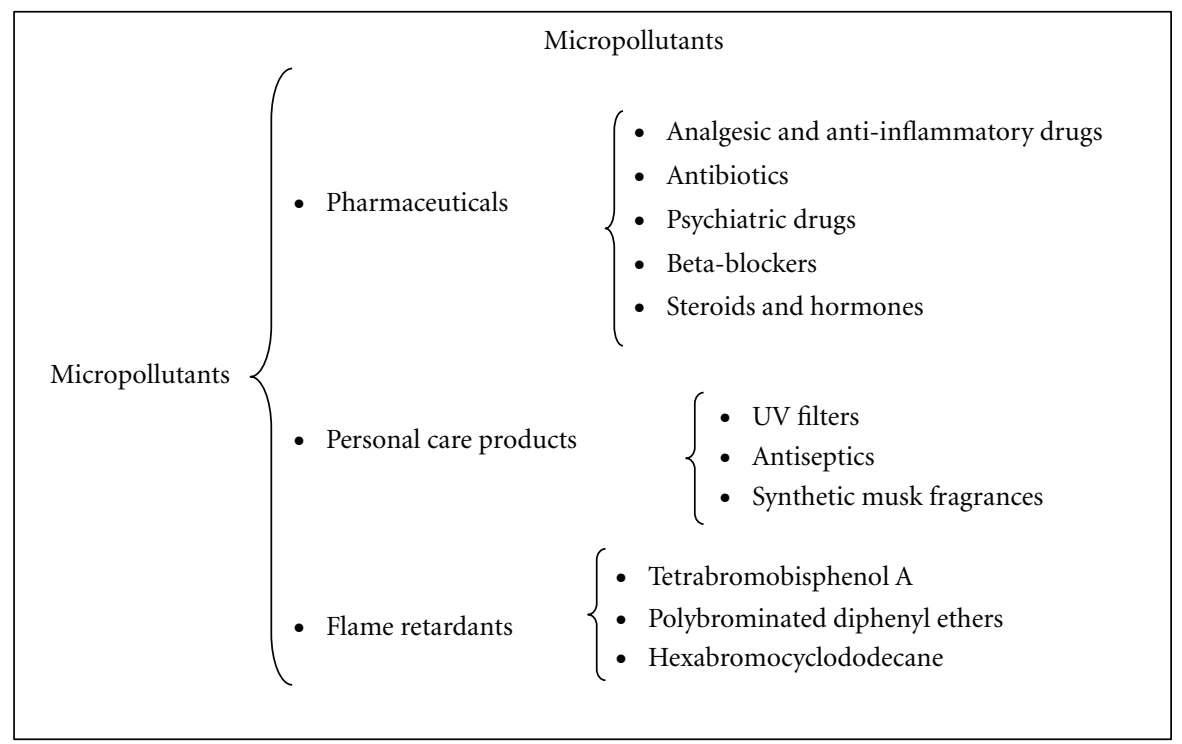

FIGURE 1: Scheme summary of the micropollutants considered in this paper.

2.1.1. Liquid Samples. Methods of sample preparation and extraction for pharmaceuticals have evolved significantly for aqueous phases since they were first described as early as the late 1980s. The traditional sample preparation method, liquid-liquid extraction (LLE), has largely been replaced by solid-phase extraction (SPE) for the aqueous matrices.

Regarding separation and detection techniques, LC, combined with MS or $\mathrm{MS}^{2}$, is the most suitable technique to separate and detect pharmaceutical residues or metabolites in environmental samples. Most of the pharmaceutical compounds are not very volatile and some are highly polar, containing ionizable functional groups. It requires additional derivatization steps that may involve more labor and time, and cause unwanted contamination in the sample. Many antibiotics are nonvolatile with a high molecular weight, which respond well to ESI interface operating in the positive ion mode of ionization; therefore LC-MS or LC-MS ${ }^{2}$ is often selected for their separation and analysis. When using a single MS step, selected-ion monitoring, SIM, is preferred for increased analytical sensitivity and selectivity in complex matrices such as wastewaters. Choi et al. [40] applied this methodology for the simultaneous analysis of seven tetracycline antibiotics and sulfonamide antibiotics from agricultural wastewater samples and sewage effluent samples. They combined the pretreatment technique, SPE, with LCMS through online connection. This type of connection suppressed the target loss by keeping the cartridge from drying, which resulted in improvement on the recovery and saving of the analytical time. The average LOQ achieved was between 0.09 and $0.11 \mu \mathrm{g} \cdot \mathrm{L}^{-1}$ for tetracycline antibiotics and sulfonamide antibiotics, respectively. Chen et al. [41], using IT-MS, reached LODs in the range of $3.2-6.2 \mathrm{ng} \cdot \mathrm{L}^{-1}$ when they determined fluoroquinolones in water samples. The target compounds were extracted from samples by molecularly imprinted polymer (MIP) as sorbent. ESI was performed in positive mode and the data acquisition was performed in multiple reaction monitoring (MRM).

Some works can be found in the bibliography which use hybrid quadrupole instruments coupled to conventional liquid chromatography systems for the analysis of pharmaceuticals in waters. For instance, Martínez Bueno et al. [42] developed a method for the determination of 38 pharmaceuticals and 10 metabolites by $\mathrm{LC}^{-\mathrm{MS}^{2}}$ using hybrid triple-quadrupole linear ion trap mass spectrometer in combination with time-of-flight mass spectrometry operating under SRM mode in both positive and negative ESI. This methodology was successfully applied to a monitoring study intended to characterize wastewater effluents of six sewage treatment plants in Spain. A different MS combination, QqLIT, was proposed by Gros et al. [43] for the determination of 73 pharmaceuticals by using both SRM and information-dependent analysis (IDA) acquisition modes with a total analysis time of $87 \mathrm{~min}$. The method developed was applied to the analysis of various influent and effluent wastewaters.

The combination of UHPLC with an MS detector appears to be a suitable approach that fulfills key requirements in terms of sensitivity, selectivity, and peakassignment certainty for the rapid determination of analytes at low concentrations in complex matrices. Modern QqQ instruments operating in the SRM mode are preferred for targeted analysis, while TOF-MS analyzers are particularly useful for nontargeted analysis. Batt et al. [44] developed a UHPLC method coupled to a QqQ mass spectrometer for the determination of 48 drugs and 6 metabolites in wastewater and surface waters. However, total analysis time was 48 min since four chromatographic conditions were used to determine all the compounds. Langford and Thomas [45] used UHPLC-QqQ with an ESI source; however, chromatographic separation of the 40 pharmaceuticals from 
hospital effluents took more than $50 \mathrm{~min}$. A different MS analyzer was selected by Petrovic et al. [46] who developed an UHPLC method coupled to a Q-TOF mass spectrometer for the determination of 29 pharmaceuticals in wastewater in $14 \mathrm{~min}$.

Conley et al. [47] described the determination of 13 pharmaceuticals and 1 metabolite in less than 4 min using UHPLC interfaced to a QqQ mass spectrometer with an ESI source. The mass analyzer operated in positive ionization mode for all analytes. The method was applied to samples of surface water collected from the Upper Tennessee River Basin. The same technique was applied by Kasprzyk-Hordern et al. [48] for the determination of 28 basic/neutral pharmaceuticals in river water samples from UK and Poland and fifteen compounds were determined at levels ranging from nanograms to micrograms per liter. In this case they achieved the separation of the target compounds in $16 \mathrm{~min}$.

Considerable attention had been focused on the occurrence of steroid hormones in the environment since recent studies have documented that the exposure of fish to municipal wastewater effluents affects the reproductive physiology and behavior in many fish species at $\mathrm{ng} \cdot \mathrm{L}^{-1}$ or even $\mathrm{pg} \cdot \mathrm{L}^{-1}$ levels [49, 50]. Chang et al. [51] developed a method for the simultaneous determination of eighteen androgens and progestogens in environmental waters by using UHPLC$\mathrm{MS}^{2}$. Mass spectrometry was performed using a triplequadrupole detector which was operated with ESI in the positive ion mode. After SPE procedure, a silica cartridge was used to purify the extract and reduce the signal suppression due to coeluting interferences. The developed method was applied to the analysis of these compounds in wastewater and surface-water samples and LODs for the eighteen analytes in the influent, effluent, and surface-water samples were in the ranges $0.20-50,0.04-20$, and $0.01-12 \mathrm{ng} \cdot \mathrm{L}^{-1}$, respectively.

Hybrid mass spectrometers have also been used in combination with UHPLC to determine pharmaceutical compounds. Recently, Huerta-Fontela et al. [52] developed a method for the determination of 49 pharmaceuticals and 6 metabolites in six wastewater treatment plants using the dual acquisition modes of a hybrid triple-quadrupole linear ion trap system. The proposed method enabled all the 55 compounds to be separated chromatographically in less than $9 \mathrm{~min}$ ( $6.3 \mathrm{~min}$ positive mode and $2.7 \mathrm{~min}$ negative mode) with a total analysis time of $18 \mathrm{~min}$.

2.1.2. Solid Samples. Despite the rather low lipophilicity of pharmaceuticals, interaction of the polar functional groups of them with organic matter and/or minerals may result in adsorption to solids. Furthermore, the application of sewage sludge as a fertilizer to the agricultural land and the reuse of manure containing veterinary medicines may also introduce pharmaceuticals into the soil. Animal origin pharmaceuticals, including aquaculture-derived compounds, contribute significantly to the occurrence of pharmaceuticals in solid matrices due to their patterns of application. Sewage sludge is the main solid produced in sewage treatment plants and the European Union (EU) promotes the use of sewage sludge as a fertilizer on agricultural land. Therefore it is important to know the occurrence of contaminants in sewage-sludge samples as those could reach surface or ground waters.

The presence of pharmaceuticals in sediment, soil, and sewage sludge has been studied extensively. Analytical methods for the determination of specific groups of pharmaceuticals, including NSAIDs, antidepressants, antibiotics, and $\beta$-blockers $[53,54]$, and multiclass methods have been reported in recent years. Soxhlet extraction method for soil or sediment has been replaced by PLE, MAE, and UAE because of the time-consuming nature and high usage of hazardous organic solvents. Sample extracts obtained from solid matrices are most of the time with interfering coextracts, which dictate an additional cleanup before LC analysis. Soil or sediment sample preparation needs to combine additional cleanup or purification steps, mainly SPE after the extraction step in the solvent due to the complexity of environmental samples $[55,56]$.

Haller et al. [57] used LC-MS and ESI with SIM mode to measure seven veterinary antibiotics in manure and reported $100 \mu \mathrm{g} \cdot \mathrm{kg}^{-1}$ as LOQ. This technique was also applied by Sagristà et al. [58] for the direct determination of four NSAIDs in dried sludge from a sewage treatment plant (Figure 2). Extraction experiments were carried out using a magnetic stirrer at $660 \mathrm{rpm}$ for several hours and then a three-phase hollow-fiber liquid-phase microextraction (HFLPME) was applied. This microextraction procedure allowed for the enrichment factors about 3000 times for all analytes. Data acquisition was performed in negative ion mode with SIM. LODs and LOQs were about 10 and $33 \mu \mathrm{g} \cdot \mathrm{L}^{-1}$, respectively.

Determination by Qq-IT, with an ESI source operated in positive mode, has been used to characterize the persistence of tetracyclines in soil fertilized with liquid manure. The analytes were extracted from soil samples by vortex with citrate buffer and ethyl acetate and the LOQ was $5 \mu \mathrm{g} \cdot \mathrm{kg}^{-1}$ for all compounds [59]. More recently, microwave-assisted micellar extraction combined with a QqQ mass spectrometer and ESI source, in a positive mode, was applied for the analysis of fluoroquinolone antibiotics in coastal marine sediments and in sewage-sludge samples. This extraction technique, which uses a micellar solution as extractant and LC-MS², allowed LODs and LOQs between $0.15-0.55 \mu \mathrm{g} \cdot \mathrm{kg}^{-1}$ and $0.49-$ $1.85 \mu \mathrm{g} \cdot \mathrm{kg}^{-1}$, respectively [60]. In addition, Jacobsen et al. [61] applied two different LC-MS ${ }^{2}$ methods to quantify eight antibiotics from different classes in soil and reported LOQs in the range $1.1-12.8 \mu \mathrm{g} \cdot \mathrm{kg}^{-1}$. Löffler and Ternes [62] used two different APCI-MS ${ }^{2}$ methods for ten acidic pharmaceuticals in negative mode and ESI-MS ${ }^{2}$ for seven antibiotics in positive mode to determine residues in river sediment. This study illustrated that different ionization methods can be adapted to the characteristics of the compounds being examined.

Estrogenic compounds are medium polar to relatively nonpolar substances, with log Kow values in the range 2.55.3. Consequently, we can expect sorption of estrogens to the suspended matter and a tendency of them to accumulate in soil and sediments. Several estradiol-mimicking compounds, including $17 \beta$-estradiol, estriol, and $17 \alpha$-ethinylestradiol, were determined from sewage-sludge samples by using MAE 


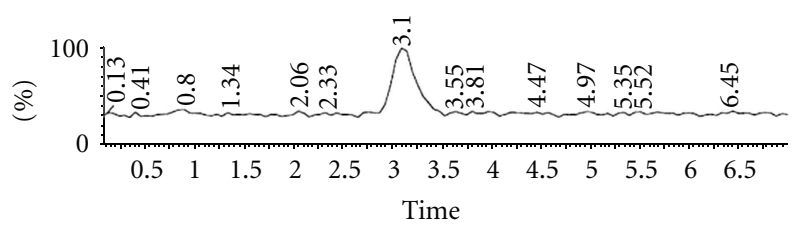

(a)

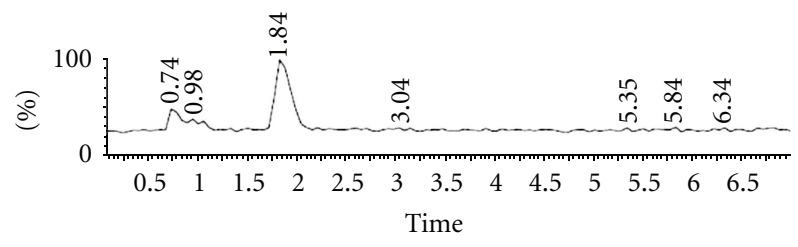

(c)

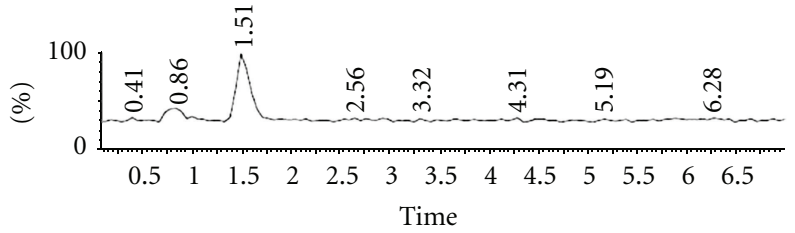

(b)

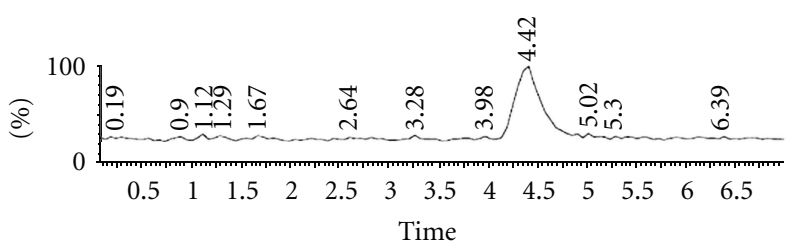

(d)

FIGURE 2: Single ion monitoring chromatograms obtained by LC-MS from reagent water spiked at $0.4 \mathrm{mg} \cdot \mathrm{L}^{-1}$. (a) $\mathrm{m} / \mathrm{z}=294$ (diclofenac), (b) $\mathrm{m} / \mathrm{z}=253$ (ketoprofen), (c) $\mathrm{m} / \mathrm{z}=229$ (naproxen), and (d) $\mathrm{m} / \mathrm{z}=205$ (ibuprofen). From reference [58].

followed by LC-MS ${ }^{2}$ with ESI in a positive mode. The method provided LODs ranging from 0.6 to $3.5 \mu \mathrm{g} \cdot \mathrm{kg}^{-1}$ [63]. A greater group of steroids, including natural and synthetic estrogens, androgens, progestogens, and glucocorticoids, were determined in the same type of sample by using UAE followed, with analysis; by rapid resolution LC-MS ${ }^{2}$. In this case, a triple quadrupole detector was used, which was operated with ESI in both negative and positive modes. LODs for the 28 analytes were $0.08-2.06 \mu \mathrm{g} \cdot \mathrm{kg}^{-1}$ [64]. LC-ESI(PI)$\mathrm{MS}^{2}$ and PLE as an extraction technique madeit possible to determine the traces of steroid hormones (including oestrogen, androgens, and progestogens) in soil with LODs in the range $0.08-0.89 \mu \mathrm{g} \cdot \mathrm{kg}^{-1}$. The results obtained showed ionization suppression for all the analytes in proportions ranging up to nearly $50 \%$ [65]. Using the same technique, with ESI (NI), Nieto et al. [66] achieved the determination of a greater number of natural and synthetic estrogens in sewage sludge. The MRM mode enabled LODs lower than $26 \mu \mathrm{g} \cdot \mathrm{kg}^{-1}$ of the dry weight of sewage sludge for most of target analytes. Using an IT-MS equipped with ESI (NI) source, after extraction by MAE, Matjicek et al. [67] carried out the simultaneous separation and determination of five hormones and their sulfate, glucuronide, and acetate conjugates in river sediments reaching LODs lower than $1 \mu \mathrm{g} \cdot \mathrm{kg}^{-1}$.

2.2. Personal Care Products. Personal care products (PCPs) constitute a group of emerging contaminants which have received a considerable attention in recent years. PCPs are regarded as being potentially hazardous compounds as many of them are ubiquitous and persistent and due to their continuous introduction might cause unwanted effects in the environment.

The principal pathway by which PCPs enter the environment is disposal in urban receiving waters from individual households, after showering and bathing. A variety of PCPs have been detected everywhere at the $\mathrm{ng} \cdot \mathrm{L}^{-1}$ concentration level in the effluents of WWTPs, since conventional watertreatment processes do not seem to be sufficient to remove
PCPs from sewage water (30-90\% efficiency) [68-74]. The occurrence of PCPs in municipal sewage effluent and other environmental samples could negatively impact the health of the ecosystem and the health of humans, due to the persistent and long-term chronic exposure of aquatic organisms to the concentrations of PCPs [68]. Moreover, there is some evidence of potential interactive effects of PCPs, so that low doses may lead to cumulative stress and synergic toxicity effects in exposed organisms $[68,75]$. PCPs, such as UV screens, insect repellents, and some synthetic musk fragrances, have also been suspected endocrine-disrupting compounds (EDCs) (i.e., compounds that can mimic the natural hormones of animals) [71, 73, 74].

Nowadays, in order to achieve greater protection to solar radiation, UV filters are added not only to cosmetics to be used for sunbathing but also to daily cosmetic products, such as face day creams, after-shave products, makeup formulations, lipsticks, and shampoos, thus resulting in an increase in the use of UV filters. Moreover, they can be found as additives in textiles, plastics, paints, car polishes, and so forth [76]. This excessive use of UV filters has led to their presence in the aquatic environment and increased their potential for endocrine and developmental toxicity [77, 78]. The increasing usage of these compounds, combined with their moderate-to-high water solubility, has led to the appearance of some of them in the aquatic environment. As regards toxicological effects, in vivo and in vitro studies have demonstrated that some hydroxylated benzophenones exert estrogenic and antiandrogenic actions [79].

Triclosan, triclocarban and methyl-triclosan are bactericides widely used in household and personal-care products, for example, shampoos, soaps, creams, mouthwash, and toothpaste [80]. Triclosan is found to be acutely toxic to some aquatic organisms and it has been also shown to photo transform into members of the dioxin family, which is known as the most carcinogenic chemicals in the world [81]. Although a relatively few data exist about the toxicity of triclocarban, it has been found to impair reproduction in laboratory rats and that some of its degradation products are 
carcinogenic. Methyl-triclosan, a metabolite of triclosan, is more lipophilic and environmentally persistent, suggesting its relatively high bioaccumulation potential in aquatic organisms [82].

Table 2 illustrates some applications of LC-MS to the determination of PCPs in environmental samples.

2.2.1. Liquid Samples. Negreira et al. [83] determined six derivatives of 2-hydroxybenzophenone, which are extensively employed as UV absorbers, in water samples by LCQqQ using ESI in positive and negative modes, except for one compound (2-hydroxy-4-methoxybenzophenone-5sulphonic acid) which could be ionized only in a negative mode. Benzophenones were recorded in MRM mode using two transitions per compound. Recoveries from the SPE step remained unaffected by the nature of the matrix; however, the efficiency of ESI was compound and sample dependant. Under optimized conditions, the proposed method provided LOQs from less than 1 to $32 \mathrm{ng} \cdot \mathrm{L}^{-1}$, depending on the compound and the type of water sample.

Triple quadrupole is the most common and most useful tool for determining PCPs in high-sensitivity target analysis. This mass spectrometer fitted with an ESI source operating in a negative mode has been used by Zhao et al. to determine triclosan and triclocarban in wastewater and tap water samples (Figure 3). Enrichment of target analytes before analysis was carried out by using ionic liquid dispersive liquid-phase microextraction. The sensitivity of the proposed method allowed for LODs in the range $0.04-0.58 \mu \mathrm{g} \cdot \mathrm{L}^{-1}$ [84]. Klein et al. determined triclocarban in wastewater effluents by LCQqQ after stir-bar sorptive extraction (SBSE) obtaining an LOQ of $10 \mathrm{ng} \cdot \mathrm{L}^{-1}$ for the target analyte [85]. ESI source was also operated in a negative mode and MRM mode was applied.

Pedrouzo et al. [86] determined eleven PCPs, including hydroxylated benzophenones, triclocarban and triclosan, and parabens, (another type of preservatives used in personal care products) by SPE and UHPLC-MS ${ }^{2}$ in surface and wastewaters in 9 minutes of chromatographic separation. A triple-quadrupole mass spectrometer and ESI in both PI and NI modes were applied. LOQ was $5 \mathrm{ng} \cdot \mathrm{L}^{-1}$ for all the compounds, except for methylparaben $\left(3 \mathrm{ng} \cdot \mathrm{L}^{-1}\right)$. Most of PCPs determined were found in influent waters being methylparaben and propylparaben found at the highest concentration. Both are the most widely used parabens and they are normally used together due to their synergistic preservative effects $[87,88]$.

By using MRM to monitor two transitions between precursor and product ions, it is possible to confirm and quantify the presence of PCPs in waters at very low levels [89]. For example, Rodil et al. [90] developed a method to determine a group of 53 multiclass emerging organic pollutants (included the types mentioned above) by LC$\mathrm{MS}^{2}$, using ESI in both PI and NI modes, after SPE. The proposed method allowed LODs between 0.3 and $30 \mathrm{ng} \cdot \mathrm{L}^{-1}$. The method was used for the simultaneous determination of target analytes in water samples, including tap, surface, and wastewater. LC-QqIT was the technique chosen for determining the presence of 84 pollutants of different classes in wastewaters, including some PCPs such as sunscreen agents and synthetic musks. Previous to LC-QqIT analysis (ESI in PI and NI modes), wastewater samples were preconcentrated by SPE [91].

2.2.2. Solid Samples. Several PCPs (e.g., triclosan, triclocarban, and most UV-filtering compounds) show affinity to solid matrices. As a consequence, to allow the correct evaluation of the ecological impact of these substances, evaluation of their prevalence in solid matrices is important. Several analytical approaches were therefore reported recently.

LC-MS ${ }^{2}$, with ESI operated in negative mode and MRM, was applied by Zhang et al. [92] to analyse benzophenone UV filters in sediment and sludge. The method developed allowed LOQs in the ranges of $0.06-0.33 \mathrm{ng} \cdot \mathrm{g}^{-1}$ dry weight $(\mathrm{dw})$ and $0.1-1.65 \mathrm{ng} \cdot \mathrm{g}^{-1} \mathrm{dw}$ for sediment and sludge samples, respectively. ESI and APCI sources, operated in the positive and in the negative ion mode using MRM, were applied by Wick et al. [93] to determine different classes of compounds such as, biocides, UV filters, and benzothiazoles in sludge samples. ESI exhibited a strong ion suppression for most target analytes, while APCI was generally less susceptible to ion suppression which led to higher signal intensities in the samples and consequently to lower LOQs as long as the background noise was not increasing.

UHPLC-MS ${ }^{2}$ was applied by Nieto et al. [94] for the determination of a group of parabens and two UV filters in sewage sludge. In the chromatographic step, after pressurized liquid extraction, the compounds were detected by using tandem mass spectrometry with a triple-quadrupole analyzer with ESI in positive and negative modes. The use of small diameter particles in the chromatographic column allowed the compounds to be eluted in $9 \mathrm{~min}$. LODs and LOQs were lower than $8 \mu \mathrm{g} \cdot \mathrm{kg}^{-1}$ and $12.5 \mu \mathrm{g} \cdot \mathrm{kg}^{-1}$ of dw, respectively.

2.3. Flame Retardants. Flame retardant (FR) compounds are a structurally diverse group of chemicals that are added to or reacted with polymers, and they are used in plastics, textiles, electronic circuitry, and other materials to reduce the risk of fire. One of these groups of compounds comprises brominated FRs (BFRs), some of which are ubiquitous, and many of which have been detected in biota, sediments, air, water, marine mammals, and even human milk $[95,96]$. BFRs are mainly represented by tetrabromobisphenol A (TBBPA), polybrominated diphenyl ethers (PBDEs), which are aromatic compounds, and the cycloaliphatic compound hexabromocyclododecane (HBCD). Regarding TBBPA, one of the most important and commonly used flame retardants, although the use of TBBPA as an additive is estimated to account for about $10 \%$ of the total amount used, excessive non-polymerized TBBPA can be emitted, contaminating the environment [97]. Mainly due to its low bioaccumulation potential, it presents concentration levels lower than those of PBDEs or HBCD in the environment [98]. However, TBBPA, being a phenolic compound, may have a greater adverse effect on humans and wildlife. Likewise, TBBPA can be considered a potential EDC due to the similarities in its structure with $17 \beta$-estradiol and thyroxine. 


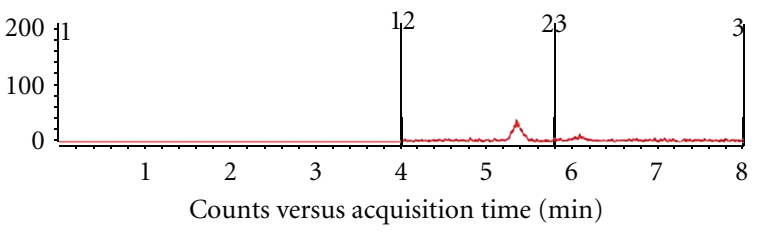

(a)

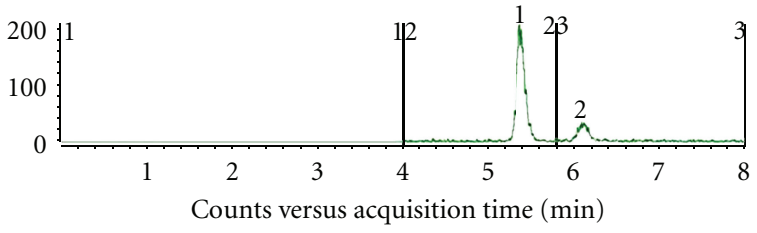

(b)

FIGURE 3: LC-ESI-MS² chromatogram obtained from wastewater. (a) Wastewater (b) Wastewater spiked with $0.40 \mu \mathrm{g} \cdot \mathrm{L}^{-1}$ triclocarban $(1)$ and $2.0 \mu \mathrm{g} \cdot \mathrm{L}^{-1}$ triclosan (2). From reference [84].

LC, coupled to tandem MS, and ESI, APCI or atmospheric pressure photoionization (APPI), represents a valid tool to the determinations of these compounds, since that the determination of some congeners is known to be difficult due to thermal degradation problems and also because a derivatisation step is needed [99-102].

Some applications of the use of LC-MS to the determination of these micropollutants in environmental samples are shown in Table 3.

2.3.1. Liquid Samples. The use of LC-MS in the determination of TBBPA provides several different detection modes and eliminates the need for the derivatization of the phenolic group. Moreover, it facilitates the use of ${ }^{13} \mathrm{C}$-labelled TBBPA. Tollbäck et al. [103] reported that the most suitable LCMS interface for TBBPA analysis is ESI operating in a negative ionization mode. ESI gave 30-40 times lower LODs compared to APCI. In addition, it permits the monitoring of the intact TBBPA molecule through the soft ionization of ESI, resulting in improved method selectivity and accuracy. Frederiksen et al. [104] compared LC-MS ${ }^{2}$ to GC-MS for the determination of TBBPA and concluded that LC-MS ${ }^{2}$ is the method of choice, not only because derivatisation is not needed, but also because of its higher sensitivity and better detection. $\mathrm{LC}^{-\mathrm{MS}^{2}}$ using QqQ and APCI source was performed for the analysis of 38 BFRs in wastewater, finding decabromodiphenylethane (DBDPE), bis(2-ethyl1-hexyl)tetrabromophthalate (BEHTBP), and TBBPA at $\mathrm{ng} \cdot \mathrm{L}^{-1}$ levels [105]. Bacaloni et al. [106] proposed an LC$\mathrm{MS}^{2}$ method for the simultaneous determination of TBBPA and five PBDEs in water samples. LIT mass spectrometer, coupled with an APPI source, was operated in the negative ion mode and each compound was quantified operating in MRM obtaining LOQs of $0.2-3.3 \mathrm{ng} \cdot \mathrm{L}^{-1}$, except for one compound. PBDEs were poorly retained by SPE from river water and sewage treatment plant effluent samples; thus LLE by $\mathrm{n}$-hexane was used for these samples.

2.3.2. Solid Samples. Due to its low solubility in water $\left(0.72 \mathrm{mg} \cdot \mathrm{L}^{-1}\right)$ and high $\log$ Kow (4.5), TBBPA is likely to be associated with suspended particulate matter once released in the water column and ultimately buried in sediments $[107,108]$. However, due to the lower bioaccumulation potential, TBBPA presents lower concentrations than PBDEs and HBCD in the environment. IT-MS was reported for the determination of TBBPA in sediment and sewage sludge after
LC separation [108]. Although the ion suppression of the TBBPA signal due to matrix components in the ESI process was not high, sewage-sludge extracts suffered greatly from ion suppression and an extensive cleanup was required to minimize this effect.

The distribution of HBCD isomers in suspended sediments from Detroit River was analyzed by QqQ, with an ESI source operated in negative mode and detection by MRM but using ASE as extraction technique [109]. LOD of $10 \mathrm{pg}$ on column was estimated for individual HBCD diastereoisomers. An LC-IT-MS method, employing ESI operated in a negative ionization mode, was developed to determine HBCD diastereoisomers in marine sediment samples, obtaining LOQs ranged from 25 to $40 \mathrm{pg} \cdot \mathrm{g}^{-1}$ (dw). Target analytes were extracted from sediment samples by MAE. Efficiency of this technique was compared with Soxhlet extraction and PLE and the results obtained showed that MAE provides better extraction efficiencies than either PLE or Soxhlet extraction [110].

LC-ESI-MS ${ }^{2}$-based method was developed by Chu et al. [107] for the simultaneous determination of TBBPA, as well as lower brominated BPA analogues, in sediment and sludge samples. LOQs for both kind of samples were in the range $0.02-0.15 \mathrm{ng} \cdot \mathrm{g}^{-1}(\mathrm{dw})$.

Hybrid mass spectrometer (LC-QqLIT) with an ESI interface was proposed by Guerra et al. to analyze TBBPA and related compounds (bisphenol A (BPA), monobromobisphenol A (MonoBBPA), dibromobisphenol A (DiBBPA), and tribromobisphenol A (TriBBPA)) in sewage-sludge and sediment samples. Sample extraction was based on the use of ultrasonication SPE, allowing for LODs in the range of $0.6-2.7 \mathrm{ng} \cdot \mathrm{g}^{-1}$ and $1.4-66 \mathrm{ng} \cdot \mathrm{g}^{-1}$ for sediment and sludge samples, respectively [111].

ESI, APPI, and APCI sources were tested in the determination of HBCDs and TBBPA in sewage-sludge samples [112]. In this study, involving the use of UHPLC-MS ${ }^{2}$ and PLE, APCI gave a higher sensitivity than APPI while for TBBPA-bis, APCI and APPI showed a similar performance. ESI was the best option for TCBPA, TBBPA, and HBCDs. Figure 4 shows the total ion current transition of target analytes using APCI as an ionization source.

\section{Conclusions and Trends}

The applications of advanced LC-MS technologies to an environmental analysis have allowed the determination of 


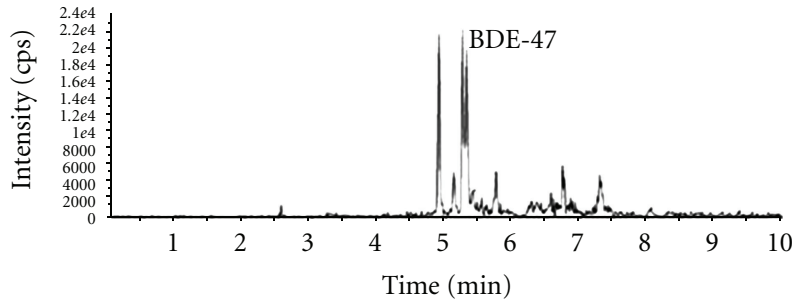

(a)

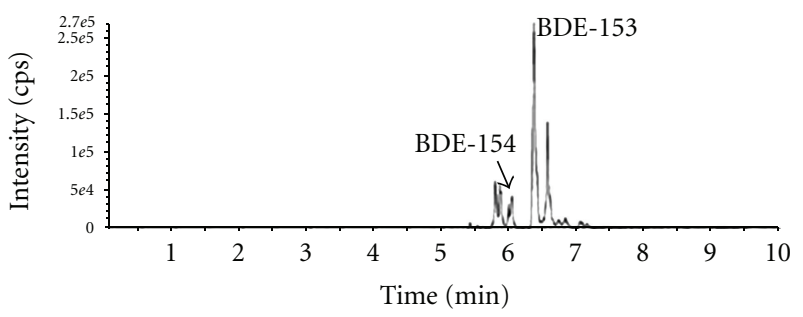

(c)

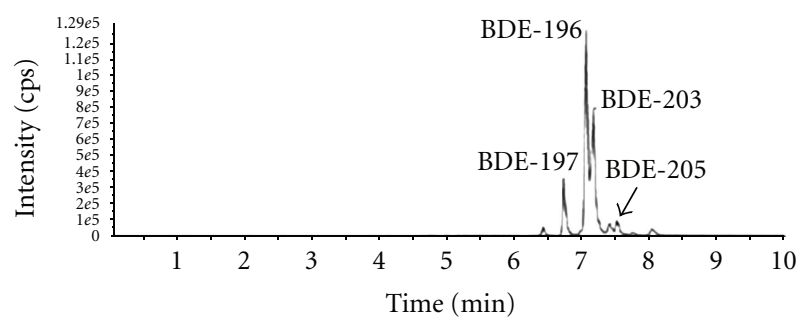

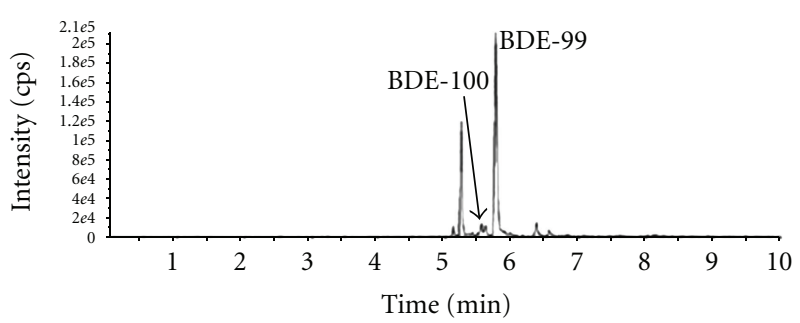

(b)

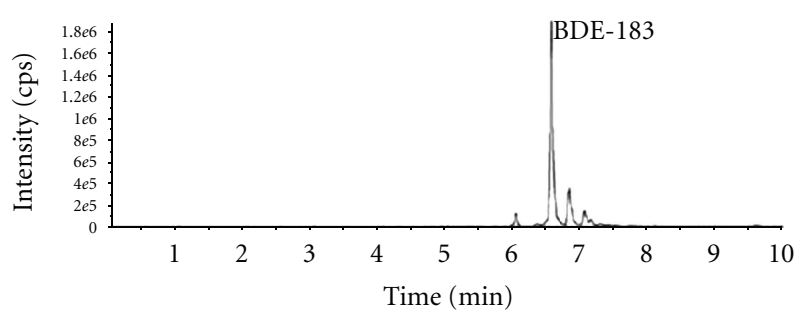

(d)

(e)

FIgure 4: TIC of transitions of tetra-BDE (a), penta-BDE (b), esa-BDE (c), epta-BDE (d), and octa-BDE (e) obtained from PLE extraction and UHPLC-APCI/MS/MS analysis of NIST Standard Reference Material New York/New Jersey Waterway Sediment 1944. From reference [112].

a great number of compounds, especially polar compounds, that were previously difficult or even impossible to analyze. In particular, the introduction of API interfaces and triplequadrupole analyzers has greatly improved the sensitivity and selectivity of detection and today, the analysis of many micropollutants in the environment samples is possible at the $\mathrm{ng} \cdot \mathrm{L}^{-1}$ and $\mathrm{ng} \cdot \mathrm{g}^{-1}$ levels, and even at the $\mathrm{pg} \cdot \mathrm{L}^{-1}$ and $\mathrm{pg} \cdot \mathrm{g}^{-1}$ levels in the routine bases. Because of the improved sensitivity and selectivity of the detection systems, a sample preparation is becoming easier, and the probe of it is the current trend towards a more extensive application of automated online methodologies with simple sample pretreatment and high sample throughput. However, despite the high selectivity of LC-MS systems, false negative findings can still occur due to the often high complexity of environmental matrices. Therefore, the application of stringent confirmation and identification criteria [113], in terms of retention time, base peak and diagnostic ions, relative abundances, and so forth, is essential.

The recent introduction of tandem mass spectrometry can help eliminate the false identification and quantification of coeluting compounds that can occur with single ion monitoring while it also reduces the amount of background noise present. More recent, the possibility to couple liquid chromatography to ion trap or the new generation of triplequadrupole and hybrid instruments such as quadrupole time-of-flight and linear traps, more and more applications for the determination of micropollutants have been described for liquid chromatography.

These new approaches are a powerful analytical technique with excellent capabilities due to their high sensitivity in a full-spectrum acquisition mode together with their resolving power and accurate-mass measurements. These features make these techniques very attractive in qualitative analysis, especially for the wide-scope screening of a large number of organic contaminants and residues at trace levels in different fields.

The fastest growing chromatography trend continues to be the use of the ultrahigh performance liquid chromatography. In addition to providing narrow peaks and improved chromatographic separations, it dramatically shortens analysis times.

In the area of sample pretreatment, an important progress has been made also with regards to the preparation techniques. The efforts have gone directed towards to obtain high recoveries and minimise interference, as well as to reduce solvent volumes and avoid the use of toxic organic solvents. Microextraction techniques allow high enrichment 


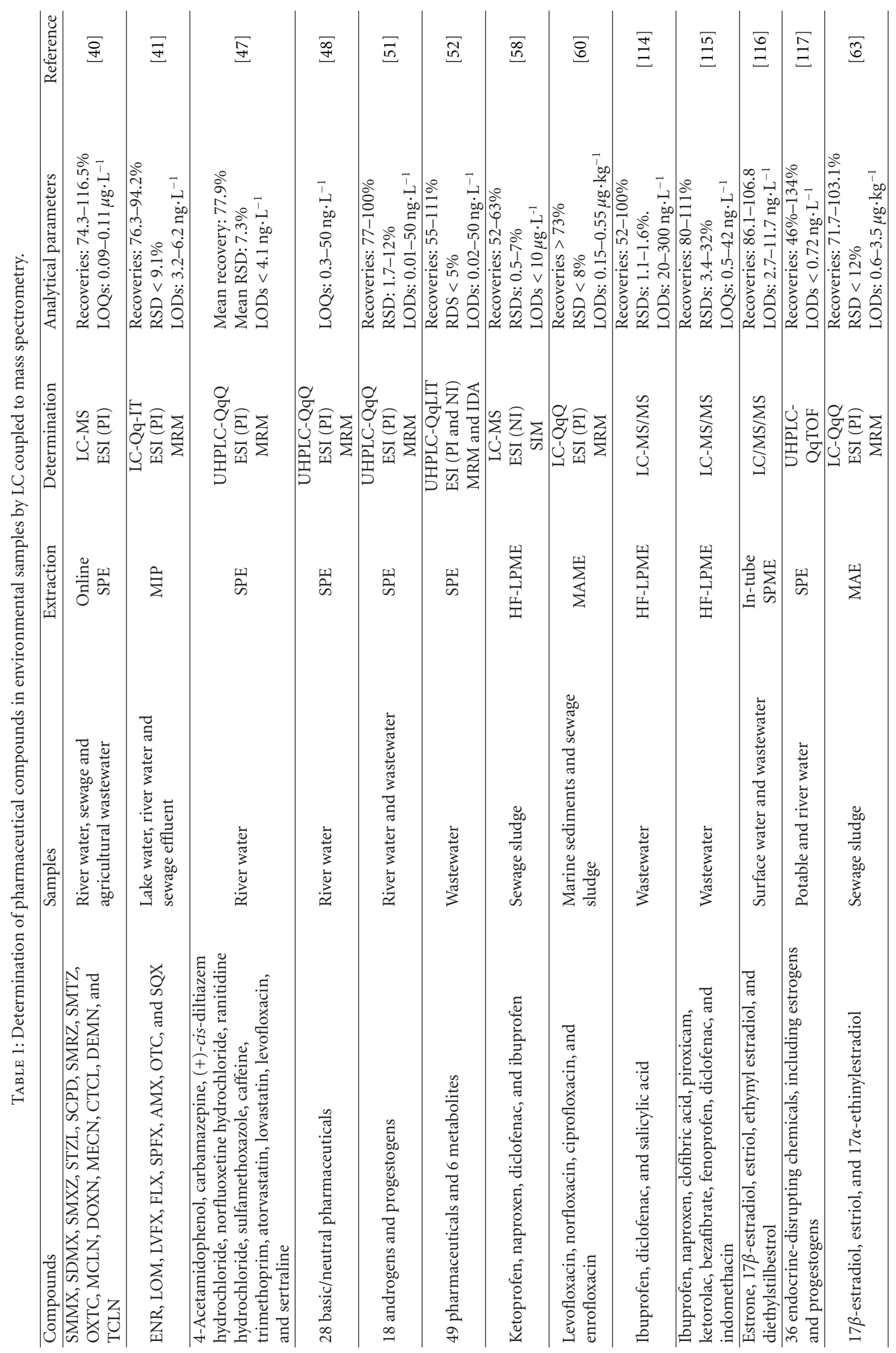




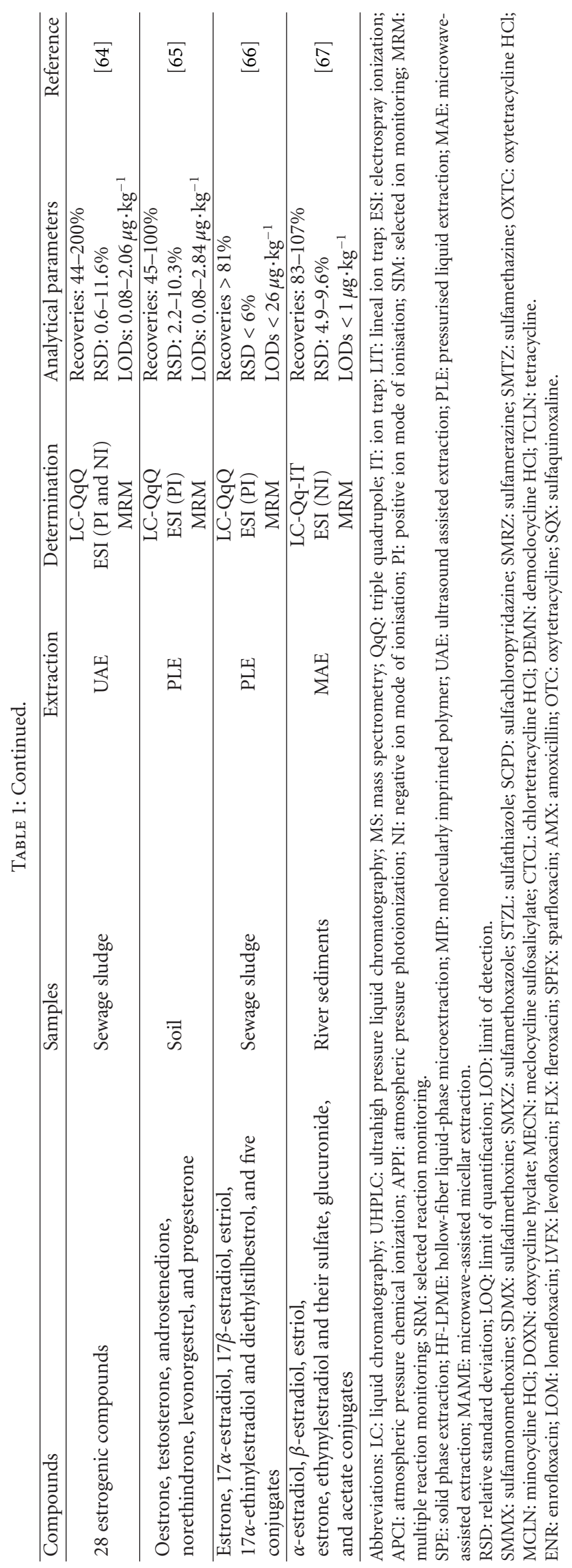




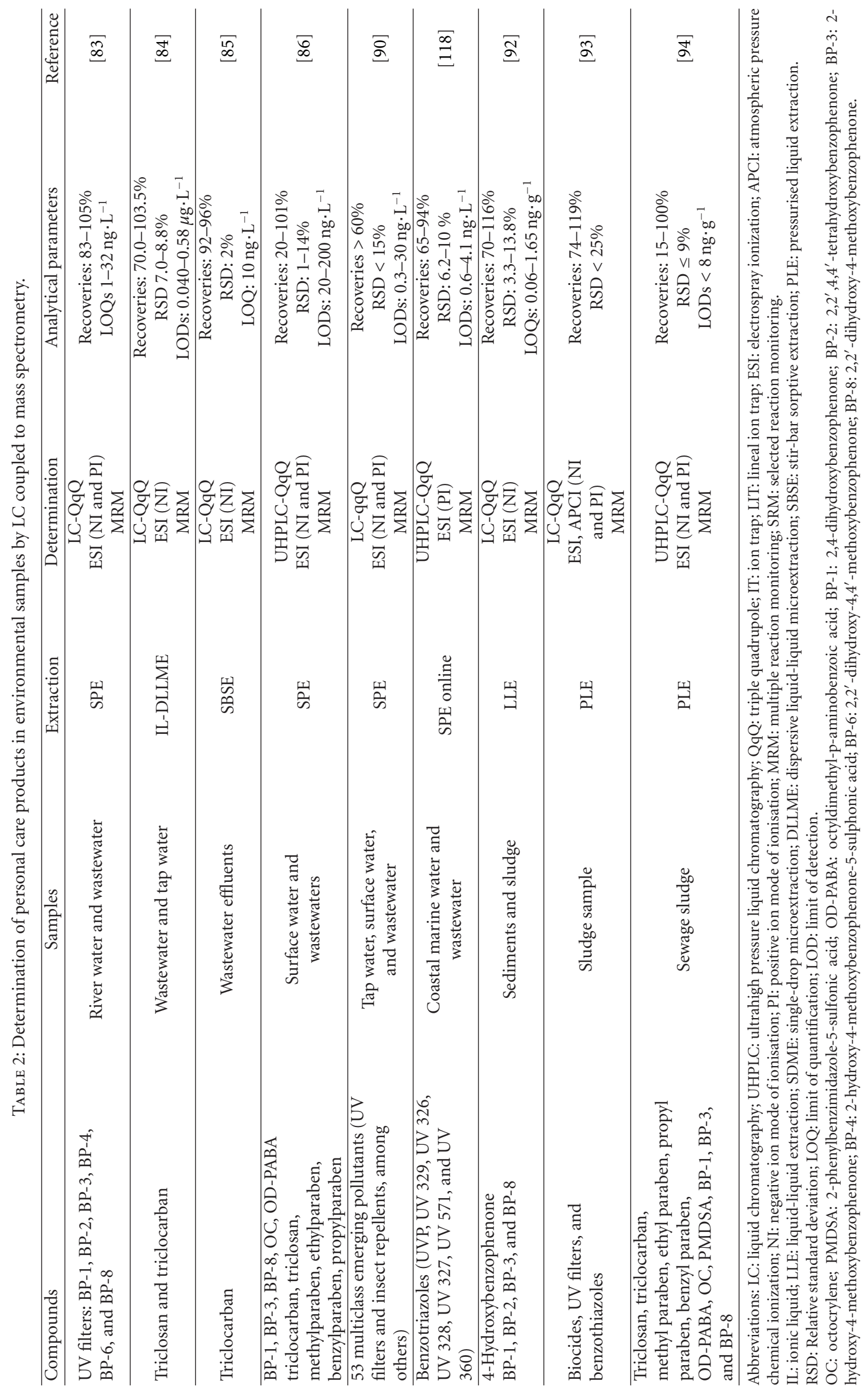




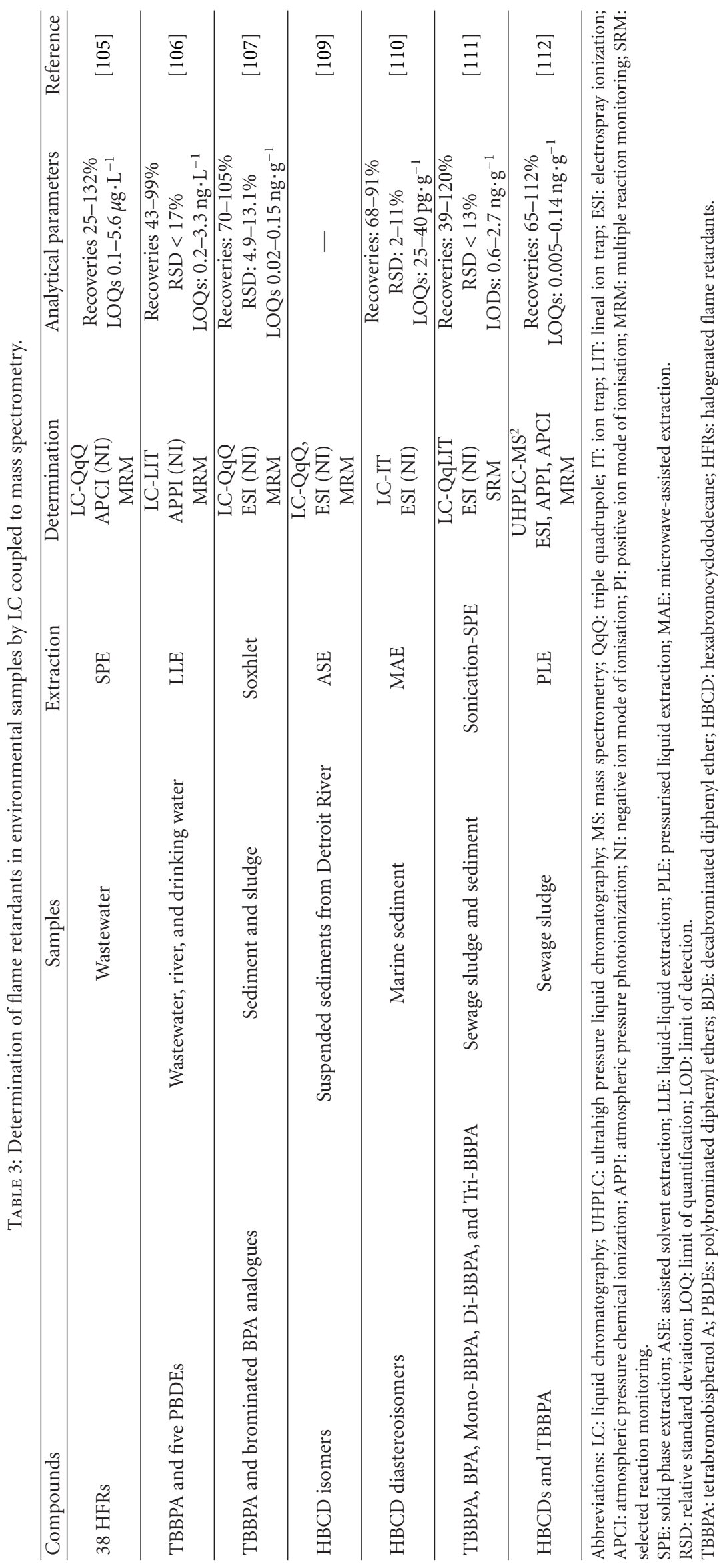


factors and minimise solvent consumption which avoid the environmental pollution.

\section{Acknowledgment}

This work was supported by funds provided by the Spanish Ministry of Science and Innovation, Research Project no. CTQ 2010-20554.

\section{References}

[1] C. Baronti, R. Curini, G. D’Ascenzo, A. Di Corcia, A. Gentili, and R. Samperi, "Monitoring natural and synthetic estrogens at activated sludge sewage treatment plants and in a receiving river water," Environmental Science and Technology, vol. 34, no. 24, pp. 5059-5066, 2000.

[2] M. J. López De Alda and D. Barceló, "Determination of steroid sex hormones and related synthetic compounds considered as endocrine disrupters in water by liquid chromatography-diode array detection-mass spectrometry," Journal of Chromatography A, vol. 892, no. 1-2, pp. 391-406, 2000.

[3] M. Seifert, G. Brenner-Weiß, S. Haindl, M. Nusser, U. Obst, and B. Hock, "A new concept for the bioeffects-related analysis of xenoestrogens: hyphenation of receptor assays with LC-MS," Fresenius' Journal of Analytical Chemistry, vol. 363, no. 8, pp. 767-770, 1999.

[4] J. Rose, H. Holbech, C. Lindholst et al., "Vitellogenin induction by $17 \beta$-estradiol and $17 \alpha$-ethinylestradiol in male zebrafish (Danio rerio)," Comparative Biochemistry and Physiology C, vol. 131, no. 4, pp. 531-539, 2002.

[5] A. Lagana, A. Bacaloni, G. Fago, and A. Marino, "Trace analysis of estrogenic chemicals in sewage effluent using liquid chromatography combined with tandem mass spectrometry," Rapid Communications in Mass Spectrometry, vol. 14, no. 6, pp. 401-407, 2000.

[6] Y. Zhou, Y. Wang, R. Wang, F. Guo, and C. Yan, "Twodimensional liquid chromatography coupled with mass spectrometry for the analysis of Lobelia chinensis Lour. using an ESI/APCI multimode ion source," Journal of Separation Science, vol. 31, no. 13, pp. 2388-2394, 2008.

[7] W. M. A. Niessen, "State-of-the-art in liquid chromatography-mass spectrometry," Journal of Chromatography A, vol. 856, no. 1-2, pp. 179-197, 1999.

[8] I. Ferrer and E. M. Thurman, "Liquid chromatography/timeof-flight/mass spectrometry (LC/TOF/MS) for the analysis of emerging contaminants," Trends in Analytical Chemistry, vol. 22, no. 10, pp. 750-756, 2003.

[9] K. Wille, H. F. De Brabander, L. Vanhaecke, E. De Wulf, P. Van Caeter, and C. R. Janssen, "Coupled chromatographic and mass-spectrometric techniques for the analysis of emerging pollutants in the aquatic environment," Trends in Analytical Chemistry, vol. 35, pp. 87-108, 2012.

[10] Y. Picó, C. Blasco, M. Farré, and D. Barceló, "Analytical utility of quadrupole time-of-flight mass spectrometry for the determination of pesticide residues in comparison with an optimized column high-performance liquid chromatography/tandem mass spectrometry method," Journal of AOAC International, vol. 92, no. 3, pp. 734-744, 2009.

[11] C. Soler, B. Hamilton, A. Furey, K. J. James, J. Mañes, and Y. Picó, "Comparison of four mass analyzers for determining carbosulfan and its metabolites in citrus by liquid chromatography/mass spectrometry," Rapid Communications in Mass Spectrometry, vol. 20, no. 14, pp. 2151-2164, 2006.
[12] D. Guillarme, UHPLC in Life Sciencies, The Royal Society of Chemistry, Cambridge, UK, 2012.

[13] M. Ibáñez, J. V. Sancho, F. Hernández, D. McMillan, and R. Rao, "Rapid non-target screening of organic pollutants in water by ultraperformance liquid chromatography coupled to time-of-light mass spectrometry," Trends in Analytical Chemistry, vol. 27, no. 5, pp. 481-489, 2008.

[14] D. Guillarme, J. Schappler, S. Rudaz, and J. L. Veuthey, "Coupling ultra-high-pressure liquid chromatography with mass spectrometry," Trends in Analytical Chemistry, vol. 29, no. 1, pp. 15-27, 2010.

[15] L. Nováková and H. Vlčková, "A review of current trends and advances in modern bio-analytical methods: chromatography and sample preparation," Analytica Chimica Acta, vol. 656, no. 1-2, pp. 8-35, 2009.

[16] L. Nováková, L. Matysová, and P. Solich, "Advantages of application of UPLC in pharmaceutical analysis," Talanta, vol. 68, no. 3, pp. 908-918, 2006.

[17] Y. F. Cheng, Z. Lu, and U. Neue, "Ulltrafast liquid chromatography/ultraviolet and liquid chromatography/tandem mass spectrometric analysis," Rapid Communications in Mass Spectrometry, vol. 15, no. 2, pp. 141-151, 2001.

[18] E. Uliyanchenko, P. J. Schoenmakers, and S. van der Wal, "Fast and efficient size-based separations of polymers using ultra-high-pressure liquid chromatography," Journal of Chromatography A, vol. 1218, no. 11, pp. 1509-1518, 2011.

[19] M. Ibáñez, J. V. Sancho, F. Hernández, D. McMillan, and R. Rao, "Rapid non-target screening of organic pollutants in water by ultraperformance liquid chromatography coupled to time-of-light mass spectrometry," Trends in Analytical Chemistry, vol. 27, no. 5, pp. 481-489, 2008.

[20] D. Vuckovic, X. Zhang, E. Cudjoe, and J. Pawliszyn, "Solidphase microextraction in bioanalysis: new devices and directions," Journal of Chromatography A, vol. 1217, no. 25, pp. 4041-4060, 2010.

[21] M. Lísa, F. Lynen, M. Holčapek, and P. Sandra, "Quantitation of triacylglycerols from plant oils using charged aerosol detection with gradient compensation," Journal of Chromatography A, vol. 1176, no. 1-2, pp. 135-142, 2007.

[22] D. Arroyo, M. C. Ortiz, L. A. Sarabia, and F. Palacios, "Determination and identification, according to European Union Decision 2002/657/EC, of malachite green and its metabolite in fish by liquid chromatography-tandem mass spectrometry using an optimized extraction procedure and three-way calibration," Journal of Chromatography A, vol. 1216, no. 29, pp. 5472-5482, 2009.

[23] T. Reemtsma and M. Jekel, Eds., Organic Pollutants in the Water Cycle, Wiley VCH, Weinheim, Germany, 2006.

[24] T. Reemtsma, S. Weiss, J. Mueller et al., "Polar pollutants entry into the water cycle by municipal wastewater: a European perspective," Environmental Science and Technology, vol. 40, no. 17, pp. 5451-5458, 2006.

[25] M. L. Farré, S. Pérez, L. Kantiani, and D. Barceló, "Fate and toxicity of emerging pollutants, their metabolites and transformation products in the aquatic environment," Trends in Analytical Chemistry, vol. 27, no. 11, pp. 991-1007, 2008.

[26] A. B. A. Boxall, C. J. Sinclair, K. Fenner, D. Kolpin, and S. J. Maund, "When synthetic chemicals degrade in the environment," Environmental Science and Technology, vol. 38, no. 19, pp. 368-375, 2004.

[27] S. Rodriguez-Mozaz, M. J. Lopez de Alda, and D. Barceló, "Advantages and limitations of on-line solid phase extraction coupled to liquid chromatography-mass spectrometry 
technologies versus biosensors for monitoring of emerging contaminants in water," Journal of Chromatography A, vol. 1152, no. 1-2, pp. 97-115, 2007.

[28] T. Kumazawa, X. P. Lee, K. Sato, and O. Suzuki, "Solid-phase microextraction and liquid chromatography/mass spectrometry in drug analysis," Analytica Chimica Acta, vol. 492, no. 1-2, pp. 49-67, 2003.

[29] S. Pedersen-Bjergaard and K. E. Rasmussen, "Bioanalysis of drugs by liquid-phase microextraction coupled to separation techniques," Journal of Chromatography B, vol. 817, no. 1, pp. 3-12, 2005.

[30] C. Mahugo-Santana, Z. Sosa-Ferrera, M. E. Torres-Padrón, and J. J. Santana-Rodríguez, "Application of new approaches to liquid-phase microextraction for the determination of emerging pollutants," Trends in Analytical Chemistry, vol. 30, no. 5, pp. 731-748, 2011.

[31] S. D. Richardson and T. A. Ternes, "Water analysis: emerging contaminants and current issues," Analytical Chemistry, vol. 83, no. 12, pp. 4616-4648, 2011.

[32] D. Barceló and N. Petróvic, "Reducing the environmental risk from emerging pollutants," Trends in Analytical Chemistry, vol. 25, no. 3, pp. 191-193, 2006.

[33] K. Kümmerer and K. Kümmerer, Pharmaceuticals in the Environment, Springer Verlag, Heidelberg, Germany, 2nd edition, 2004.

[34] T. Kosjek, E. Heath, and B. Kompare, "Removal of pharmaceutical residues in a pilot wastewater treatment plant," Analytical and Bioanalytical Chemistry, vol. 387, no. 4, pp. 1379-1387, 2007.

[35] D. Barceló, "Pharmaceutical-residue analysis," Trends in Analytical Chemistry, vol. 26, no. 6, pp. 454-455, 2007.

[36] T. A. Ternes, W. Giger, and A. Joss, "Chapter1: introduction," in Human Pharmaceuticals, T. A. Ternes and A. Joss, Eds., pp. 1-13, Hormones and Fragrances, IWA Publishing, London, UK, 2006.

[37] T. A. Ternes, "Occurrence of drugs in German sewage treatment plants and rivers," Water Research, vol. 32, no. 11, pp. 3245-3260, 1998.

[38] C. D. Metcalfe, B. G. Koenig, D. T. Bennie, M. Servos, T. A. Ternes, and R. Hirsch, "Occurrence of neutral and acidic drugs in the effluents of canadian sewage treatment plants," Environmental Toxicology and Chemistry, vol. 22, no. 12, pp. 2872-2880, 2003.

[39] T. A. Ternes, M. Meisenheimer, D. McDowell et al., "Removal of pharmaceuticals during drinking water treatment," Environmental Science and Technology, vol. 36, no. 17, pp. 38553863, 2002.

[40] K. J. Choi, S. G. Kim, C. W. Kim, and S. H. Kim, "Determination of antibiotic compounds in water by online SPE-LC/MSD," Chemosphere, vol. 66, no. 6, pp. 977-984, 2007.

[41] L. Chen, X. Zhang, Y. Xu et al., "Determination of fluoroquinolone antibiotics in environmental water samples based on magnetic molecularly imprinted polymer extraction followed by liquid chromatography-tandem mass spectrometry," Analytica Chimica Acta, vol. 662, no. 1, pp. 31-38, 2010.

[42] M. J. Martínez Bueno, A. Agüera, M. J. Gómez, M. D. Hernando, J. F. García-Reyes, and A. R. FernándezAlba, "Application of liquid chromatography/quadrupolelinear ion trap mass spectrometry and time-of-flight mass spectrometry to the determination of pharmaceuticals and related contaminants in wastewater," Analytical Chemistry, vol. 79, no. 24, pp. 9372-9384, 2007.
[43] M. Gros, M. Petrović, and D. Barceló, "Tracing pharmaceutical residues of different therapeutic classes in environmental waters by using liquid chromatography/quadrupole-linear ion trap mass spectrometry and automated library searching," Analytical Chemistry, vol. 81, no. 3, pp. 898-912, 2009.

[44] A. L. Batt, M. S. Kostich, and J. M. Lazorchak, "Analysis of ecologically relevant pharmaceuticals in wastewater and surface water using selective solid-phase extraction and UPLC-MS/MS," Analytical Chemistry, vol. 80, no. 13, pp. 5021-5030, 2008.

[45] K. H. Langford and K. V. Thomas, "Determination of pharmaceutical compounds in hospital effluents and their contribution to wastewater treatment works," Environment International, vol. 35, no. 5, pp. 766-770, 2009.

[46] M. Petrovic, M. Gros, and D. Barcelo, "Multi-residue analysis of pharmaceuticals in wastewater by ultra-performance liquid chromatography-quadrupole-time-of-flight mass spectrometry," Journal of Chromatography A, vol. 1124, no. 1-2, pp. 68-81, 2006.

[47] J. M. Conley, S. J. Symes, S. A. Kindelberger, and S. M. Richards, "Rapid liquid chromatography-tandem mass spectrometry method for the determination of a broad mixture of pharmaceuticals in surface water," Journal of Chromatography A, vol. 1185, no. 2, pp. 206-215, 2008.

[48] B. Kasprzyk-Hordern, R. M. Dinsdale, and A. J. Guwy, "Multi-residue method for the determination of basic/neutral pharmaceuticals and illicit drugs in surface water by solid-phase extraction and ultra performance liquid chromatography-positive electrospray ionisation tandem mass spectrometry," Journal of Chromatography A, vol. 1161, no. 1-2, pp. 132-145, 2007.

[49] E. F. Orlando, A. S. Kolok, G. A. Binzcik et al., "Endocrinedisrupting effects of cattle feedlot effluent on an aquatic sentinel species, the fathead minnow," Environmental Health Perspectives, vol. 112, no. 3, pp. 353-358, 2004.

[50] P. W. Sorensen, M. Pinillos, and A. P. Scott, "Sexually mature male goldfish release large quantities of androstenedione into the water where it functions as a pheromone," General and Comparative Endocrinology, vol. 140, no. 3, pp. 164-175, 2005.

[51] H. Chang, S. Wu, J. Hu, M. Asami, and S. Kunikane, "Trace analysis of androgens and progestogens in environmental waters by ultra-performance liquid chromatographyelectrospray tandem mass spectrometry," Journal of Chromatography A, vol. 1195, no. 1-2, pp. 44-51, 2008.

[52] M. Huerta-Fontela, M. T. Galceran, and F. Ventura, "Fast liquid chromatography-quadrupole-linear ion trap mass spectrometry for the analysis of pharmaceuticals and hormones in water resources," Journal of Chromatography A, vol. 1217, no. 25, pp. 4212-4222, 2010.

[53] E. Pérez-Carrera, M. Hansen, V. M. León et al., "Multiresidue method for the determination of 32 human and veterinary pharmaceuticals in soil and sediment by pressurized-liquid extraction and LC-MS/MS," Analytical and Bioanalytical Chemistry, vol. 398, no. 3, pp. 1173-1184, 2010.

[54] J. Antonić and E. Heath, "Determination of NSAIDs in river sediment samples," Analytical and Bioanalytical Chemistry, vol. 387, no. 4, pp. 1337-1342, 2007.

[55] A. Göbel, A. Thomsen, C. S. McArdell et al., "Extraction and determination of sulfonamides, macrolides, and trimethoprim in sewage sludge," Journal of Chromatography A, vol. 1085, no. 2, pp. 179-189, 2005.

[56] A. M. Jacobsen and B. Halling-Sørensen, "Multi-component analysis of tetracyclines, sulfonamides and tylosin in swine 
manure by liquid chromatography-tandem mass spectrometry," Analytical and Bioanalytical Chemistry, vol. 384, no. 5, pp. 1164-1174, 2006.

[57] M. Y. Haller, S. R. Müller, C. S. McArdell, A. C. Alder, and M. J. F. Suter, "Quantification of veterinary antibiotics (sulfonamides and trimethoprim) in animal manure by liquid chromatography-mass spectrometry," Journal of Chromatography A, vol. 952, no. 1-2, pp. 111-120, 2002.

[58] E. Sagristà, E. Larsson, M. Ezoddin, M. Hidalgo, V. Salvadó, and J. Å. Jönsson, "Determination of non-steroidal antiinflammatory drugs in sewage sludge by direct hollow fiber supported liquid membrane extraction and liquid chromatography-mass spectrometry," Journal of Chromatography $A$, vol. 1217, no. 40, pp. 6153-6158, 2010.

[59] G. Hamscher, S. Sczesny, H. Höper, and H. Nau, "Determination of persistent tetracycline residues in soil fertilized with liquid manure by high-performance liquid chromatography with electrospray ionization tandem mass spectrometry," Analytical Chemistry, vol. 74, no. 7, pp. 1509-1518, 2002.

[60] S. Montesdeoca-Esponda, Z. Sosa-Ferrera, and J. J. SantanaRodríguez, "Combination of microwave-assisted micellar extraction with liquid chromatography tandem mass spectrometry for the determination of fluoroquinolone antibiotics in coastal marine sediments and sewage sludges samples," Biomedical Chromatography, vol. 26, no. 1, pp. 33-40, 2012.

[61] A. M. Jacobsen, B. Halling-Sørensen, F. Ingerslev, and S. H. Hansen, "Simultaneous extraction of tetracycline, macrolide and sulfonamide antibiotics from agricultural soils using pressurised liquid extraction, followed by solidphase extraction and liquid chromatography-tandem mass spectrometry," Journal of Chromatography A, vol. 1038, no. 1-2, pp. 157-170, 2004.

[62] D. Löffler and T. A. Ternes, "Determination of acidic pharmaceuticals, antibiotics and ivermectin in river sediment using liquid chromatography-tandem mass spectrometry," Journal of Chromatography A, vol. 1021, no. 1-2, pp. 133-144, 2003.

[63] T. Vega-Morales, Z. Sosa-Ferrera, and J. J. SantanaRodríguez, "Determination of various estradiol mimickingcompounds in sewage sludge by the combination of microwave-assisted extraction and LC-MS/MS," Talanta, vol. 85, no. 4, pp. 1825-1834, 2011.

[64] S. Liu, G. G. Ying, J. L. Zhao et al., "Trace analysis of 28 steroids in surface water, wastewater and sludge samples by rapid resolution liquid chromatography-electrospray ionization tandem mass spectrometry," Journal of Chromatography A, vol. 1218, no. 10, pp. 1367-1378, 2011.

[65] N. Gineys, B. Giroud, and E. Vulliet, "Analytical method for the determination of trace levels of steroid hormones and corticosteroids in soil, based on PLE/SPE/LC-MS/MS," Analytical and Bioanalytical Chemistry, vol. 397, no. 6, pp. 2295-2302, 2010.

[66] A. Nieto, F. Borrull, E. Pocurull, and R. M. Marcé, "Determination of natural and synthetic estrogens and their conjugates in sewage sludge by pressurized liquid extraction and liquid chromatography-tandem mass spectrometry," Journal of Chromatography A, vol. 1213, no. 2, pp. 224-230, 2008.

[67] D. Matejicek, P. Houserová, and V. Kubáň, "Combined isolation and purification procedures prior to the highperformance liquid chromatographic-ion-trap tandem mass spectrometric determination of estrogens and their conjugates in river sediments," Journal of Chromatography A, vol. 1171, no. 1-2, pp. 80-89, 2007.
[68] C. G. Daughton, "Non-regulated water contaminants: emerging research," Environmental Impact Assessment Review, vol. 24, no. 7-8, pp. 711-732, 2004.

[69] J. B. Ellis, "Pharmaceutical and personal care products (PPCPs) in urban receiving waters," Environmental Pollution, vol. 144, no. 1, pp. 184-189, 2006.

[70] T. A. Ternes, A. Joss, and H. Siegrist, "Scrutinizing pharmaceuticals and personal care products in wastewater treatment," Environmental Science and Technology, vol. 38, no. 20, 2004.

[71] Y. Yoon, P. Westerhoff, S. A. Snyder, and E. C. Wert, "Nanofiltration and ultrafiltration of endocrine disrupting compounds, pharmaceuticals and personal care products," Journal of Membrane Science, vol. 270, no. 1-2, pp. 88-100, 2006.

[72] M. Carballa, F. Omil, J. M. Lema et al., "Behavior of pharmaceuticals, cosmetics and hormones in a sewage treatment plant," Water Research, vol. 38, no. 12, pp. 2918-2926, 2004.

[73] P. Westerhoff, Y. Yoon, S. Snyder, and E. Wert, "Fate of endocrine-disruptor, pharmaceutical, and personal care product chemicals during simulated drinking water treatment processes," Environmental Science and Technology, vol. 39, no. 17, pp. 6649-6663, 2005.

[74] S. A. Snyder, S. Adham, A. M. Redding et al., "Role of membranes and activated carbon in the removal of endocrine disruptors and pharmaceuticals," Desalination, vol. 202, no. 1-3, pp. 156-181, 2007.

[75] M. Grung, R. Lichtenthaler, M. Ahel, K. E. Tollefsen, K. Langford, and K. V. Thomas, "Effects-directed analysis of organic toxicants in wastewater effluent from Zagreb, Croatia," Chemosphere, vol. 67, no. 1, pp. 108-120, 2007.

[76] D. L. Giokas, A. Salvador, and A. Chisvert, "UV filters: from sunscreens to human body and the environment," Trends in Analytical Chemistry, vol. 26, no. 5, pp. 360-374, 2007.

[77] M. Schlumpf, P. Schmid, S. Durrer et al., "Endocrine activity and developmental toxicity of cosmetic UV filters - An update," Toxicology, vol. 205, no. 1-2, pp. 113-122, 2004.

[78] M. Schlumpf, S. Durrer, O. Faass et al., "Developmental toxicity of UV filters and environmental exposure: a review," International Journal of Andrology, vol. 31, no. 2, pp. 144-150, 2008.

[79] P. Y. Kunz, H. F. Galicia, and K. Fent, "Comparison of in vitro and in vivo estrogenic activity of UV filters in fish," Toxicological Sciences, vol. 90, no. 2, pp. 349-361, 2006.

[80] S. Chu and C. D. Metcalfe, "Simultaneous determination of triclocarban and triclosan in municipal biosolids by liquid chromatography tandem mass spectrometry," Journal of Chromatography A, vol. 1164, no. 1-2, pp. 212-218, 2007.

[81] E. Engelhaupt, "Happy birthday, love canal," Environmental Science and Technology, vol. 42, no. 22, pp. 8179-8186, 2008.

[82] M. A. Coogan, R. E. Edziyie, T. W. La Point, and B. J. Venables, "Algal bioaccumulation of triclocarban, triclosan, and methyl-triclosan in a North Texas wastewater treatment plant receiving stream," Chemosphere, vol. 67, no. 10, pp. 1911-1918, 2007.

[83] N. Negreira, I. Rodríguez, M. Ramil, E. Rubí, and R. Cela, "Solid-phase extraction followed by liquid chromatographytandem mass spectrometry for the determination of hydroxylated benzophenone UV absorbers in environmental water samples," Analytica Chimica Acta, vol. 654, no. 2, pp. 162170, 2009.

[84] R. S. Zhao, X. Wang, J. Sun, S. S. Wang, J. P. Yuan, and X. K. Wang, "Trace determination of triclosan and triclocarban in environmental water samples with ionic liquid dispersive 
liquid-phase microextraction prior to HPLC-ESI-MS-MS," Analytical and Bioanalytical Chemistry, vol. 397, no. 4, pp. 1627-1633, 2010.

[85] D. R. Klein, D. F. Flannelly, and M. M. Schultz, "Quantitative determination of triclocarban in wastewater effluent by stir bar sorptive extraction and liquid desorption-liquid chromatography-tandem mass spectrometry." Journal of Chromatography A, vol. 1217, no. 11, pp. 1742-1747, 2010.

[86] M. Pedrouzo, F. Borrull, R. M. Marcé, and E. Pocurull, "Ultra-high-performance liquid chromatography-tandem mass spectrometry for determining the presence of eleven personal care products in surface and wastewaters," Journal of Chromatography A, vol. 1216, no. 42, pp. 6994-7000, 2009.

[87] A. M. Peck, "Analytical methods for the determination of persistent ingredients of personal care products in environmental matrices," Analytical and Bioanalytical Chemistry, vol. 386, no. 4, pp. 907-939, 2006.

[88] M. Borremans, J. Van Loco, P. Roos, and L. Goeyens, "Validation of HPLC Analysis of 2-Phenoxyethanol, 1Phenoxypropan-2-ol, Methyl, Ethyl, Propyl, Butyl and Benzyl 4-Hydroxybenzoate (Parabens) in Cosmetic Products, with Emphasis on Decision Limit and Detection Capability," Chromatographia, vol. 59, no. 1-2, pp. 47-53, 2004.

[89] B. Kasprzyk-Hordern, R. M. Dinsdale, and A. J. Guwy, "The occurrence of pharmaceuticals, personal care products, endocrine disruptors and illicit drugs in surface water in South Wales, UK," Water Research, vol. 42, no. 13, pp. 34983518, 2008.

[90] R. Rodil, J. B. Quintana, P. López-Mahía, S. MuniateguiLorenzo, and D. Prada-Rodríguez, "Multi-residue analytical method for the determination of emerging pollutants in water by solid-phase extraction and liquid chromatographytandem mass spectrometry," Journal of Chromatography A, vol. 1216, no. 14, pp. 2958-2969, 2009.

[91] R. Rosal, A. Rodríguez, J. A. Perdigón-Melón et al., “Occurrence of emerging pollutants in urban wastewater and their removal through biological treatment followed by ozonation," Water Research, vol. 44, no. 2, pp. 578-588, 2010.

[92] Z. Zhang, N. Ren, Y. F. Li, T. Kunisue, D. Gao, and K. Kannan, "Determination of benzotriazole and benzophenone UV filters in sediment and sewage sludge," Environmental Science and Technology, vol. 45, no. 9, pp. 3909-3916, 2011.

[93] A. Wick, G. Fink, and T. A. Ternes, "Comparison of electrospray ionization and atmospheric pressure chemical ionization for multi-residue analysis of biocides, UV-filters and benzothiazoles in aqueous matrices and activated sludge by liquid chromatography-tandem mass spectrometry," Journal of Chromatography A, vol. 1217, no. 14, pp. 2088-2103, 2010.

[94] A. Nieto, F. Borrull, R. M. Marcé, and E. Pocurull, "Determination of personal care products in sewage sludge by pressurized liquid extraction and ultra high performance liquid chromatography-tandem mass spectrometry," Journal of Chromatography A, vol. 1216, no. 30, pp. 5619-5625, 2009.

[95] C. A. de Wit, M. Alaee, and D. C. G. Muir, "Levels and trends of brominated flame retardants in the Arctic," Chemosphere, vol. 64, no. 2, pp. 209-233, 2006.

[96] WHO Environmental Health Criteria 192, Flame Retardants, General Introduction, World Health Organization, Geneva, Switzerland, 1997.

[97] WHO, Environmental Health Criteria 172, WHO/IPCS, Geneva, Switzerland, 1995.

[98] A. Covaci, S. Voorspoels, M. A. E. Abdallah, T. Geens, S. Harrad, and R. J. Law, "Analytical and environmental aspects of the flame retardant tetrabromobisphenol-A and its derivatives," Journal of Chromatography A, vol. 1216, no. 3, pp. 346-363, 2009.

[99] A. Covaci, S. Voorspoels, and J. de Boer, "Determination of brominated flame retardants, with emphasis on polybrominated diphenyl ethers (PBDEs) in environmental and human samples - A review," Environment International, vol. 29, no. 6, pp. 735-756, 2003.

[100] R. Cariou, J. P. Antignac, L. Debrauwer et al., "Comparison of analytical strategies for the chromatographic and mass spectrometric measurement of brominated flame retardants: 1 . Polybrominated diphenylethers," Journal of Chromatographic Science, vol. 44, no. 8, pp. 489-497, 2006.

[101] A. Riu, D. Zalko, and L. Debrauwer, "Study of polybrominated diphenyl ethers using both positive and negative atmospheric pressure photoionization and tandem mass spectrometry," Rapid Communications in Mass Spectrometry, vol. 20, no. 14, pp. 2133-2142, 2006.

[102] T. Hayama, H. Yoshida, S. Onimaru et al., "Determination of tetrabromobisphenol a in human serum by liquid chromatography-electrospray ionization tandem mass spectrometry," Journal of Chromatography B, vol. 809, no. 1, pp. 131-136, 2004.

[103] J. Tollbäck, C. Crescenzi, and E. Dyremark, "Determination of the flame retardant tetrabromobisphenol A in air samples by liquid chromatography-mass spectrometry," Journal of Chromatography A, vol. 1104, no. 1-2, pp. 106-112, 2006.

[104] M. Frederiksen, K. Vorkamp, R. Bossi, F. Rigét, M. Dam, and B. Svensmark, "Method development for simultaneous analysis of HBCD, TBBPA, and dimethyl-TBBPA in marine biota from Greenland and the Faroe Islands," International Journal of Environmental Analytical Chemistry, vol. 87, no. 15, pp. 1095-1109, 2007.

[105] S. N. Zhou, E. J. Reiner, C. Marvin et al., "Development of liquid chromatography atmospheric pressure chemical ionization tandem mass spectrometry for analysis of halogenated flame retardants in wastewater," Analytical and Bioanalytical Chemistry, vol. 396, no. 3, pp. 1311-1320, 2010.

[106] A. Bacaloni, L. Callipo, E. Corradini et al., "Liquid chromatography-negative ion atmospheric pressure photoionization tandem mass spectrometry for the determination of brominated flame retardants in environmental water and industrial effluents," Journal of Chromatography A, vol. 1216, no. 36, pp. 6400-6409, 2009.

[107] S. Chu, G. D. Haffner, and R. J. Letcher, "Simultaneous determination of tetrabromobisphenol A, tetrachlorobisphenol A, bisphenol $\mathrm{A}$ and other halogenated analogues in sediment and sludge by high performance liquid chromatographyelectrospray tandem mass spectrometry," Journal of Chromatography A, vol. 1097, no. 1-2, pp. 25-32, 2005.

[108] R. Saint-Louis and E. Pelletier, "LC-ESI-MS-MS method for the analysis of tetrabromobisphenol A in sediment and sewage sludge," Analyst, vol. 129, no. 8, pp. 724-730, 2004.

[109] C. H. Marvin, G. T. Tomy, M. Alaee, and G. MacInnis, "Distribution of hexabromocyclododecane in Detroit River suspended sediments," Chemosphere, vol. 64, no. 2, pp. 268275, 2006.

[110] H. H. Wu, H. C. Chen, and W. H. Ding, "Combining microwave-assisted extraction and liquid chromatographyion-trap mass spectrometry for the analysis of hexabromocyclododecane diastereoisomers in marine sediments," Journal of Chromatography A, vol. 1216, no. 45, pp. 7755-7760, 2009. 
[111] P. Guerra, E. Eljarrat, and D. Barceló, "Simultaneous determination of hexabromocyclododecane, tetrabromobisphenol A, and related compounds in sewage sludge and sediment samples from Ebro River basin (Spain)," Analytical and Bioanalytical Chemistry, vol. 397, no. 7, pp. 2817-2824, 2010.

[112] G. Mascolo, V. Locaputo, and G. Mininni, "New perspective on the determination of flame retardants in sewage sludge by using ultrahigh pressure liquid chromatography-tandem mass spectrometry with different ion sources," Journal of Chromatography A, vol. 1217, no. 27, pp. 4601-4611, 2010.

[113] "Commission decision 2002/657/EC," Official Journal of the European Communities L221/8.

[114] R. Payan, M. A. B. López, R. Fernández-Torres, M. C. Mochón, and J. L. G. Ariza, "Application of hollow fiberbased liquid-phase microextraction (HF-LPME) for the determination of acidic pharmaceuticals in wastewaters," Talanta, vol. 82, no. 2, pp. 854-858, 2010.

[115] J. B. Quintana, R. Rodil, and T. Reemtsma, "Suitability of hollow fibre liquid-phase microextraction for the determination of acidic pharmaceuticals in wastewater by liquid chromatography-electrospray tandem mass spectrometry without matrix effects," Journal of Chromatography A, vol. 1061, no. 1, pp. 19-26, 2004.

[116] K. Mitani, M. Fujioka, and H. Kataoka, "Fully automated analysis of estrogens in environmental waters by in-tube solid-phase microextraction coupled with liquid chromatography-tandem mass spectrometry," Journal of Chromatography A, vol. 1081, no. 2, pp. 218-224, 2005.

[117] H.-X. Wang, Y. Zhou, and Q.-W. Jiang, "Simultaneous screening of estrogens, progestogens, and phenols and their metabolites in potable water and river water by ultra-performance liquid chromatography coupled with quadrupole time-of-flight mass spectrometry," Microchemical Journal, vol. 100, no. 1, pp. 83-94, 2012.

[118] S. Montesdeoca-Esponda, Z. Sosa-Ferrera, and J. J. SantanaRodríguez, "On-line solid-phase extraction coupled to ultraperformance liquid chromatography with tandem mass spectrometry detection for the determination of benzotriazole UV stabilizers in coastal marine and wastewater samples," Analytical and Bioanalytical Chemistry, vol. 403, no. 3, pp. 867-876, 2012. 


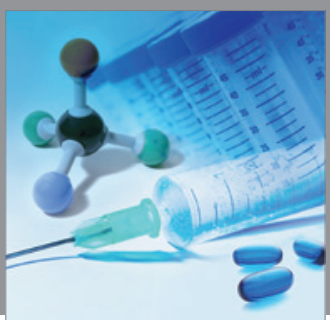

International Journal of

Medicinal Chemistry

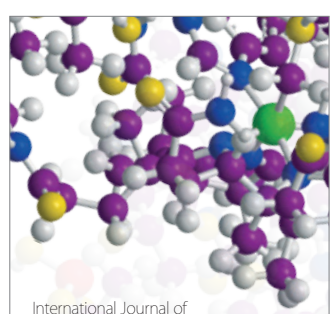

Carbohydrate Chemistry

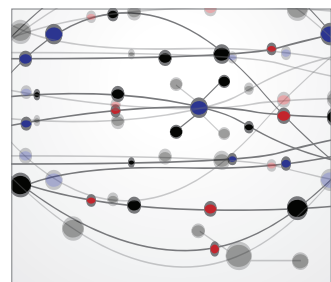

The Scientific World Journal
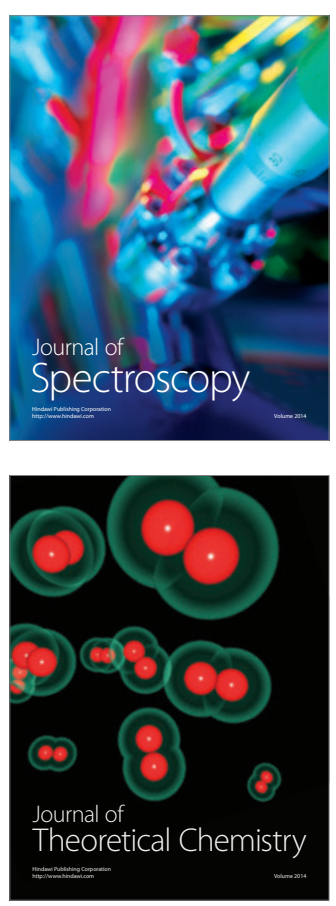
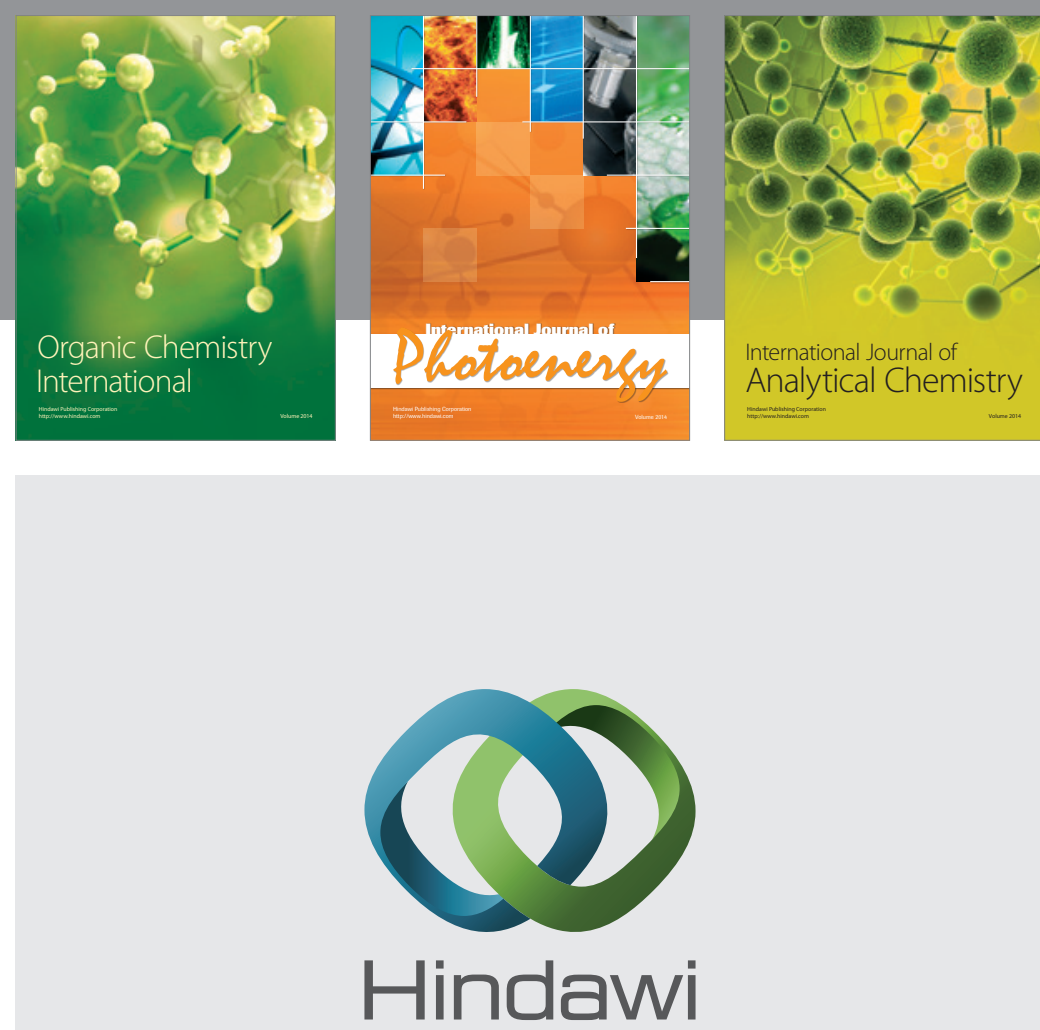

Submit your manuscripts at

http://www.hindawi.com
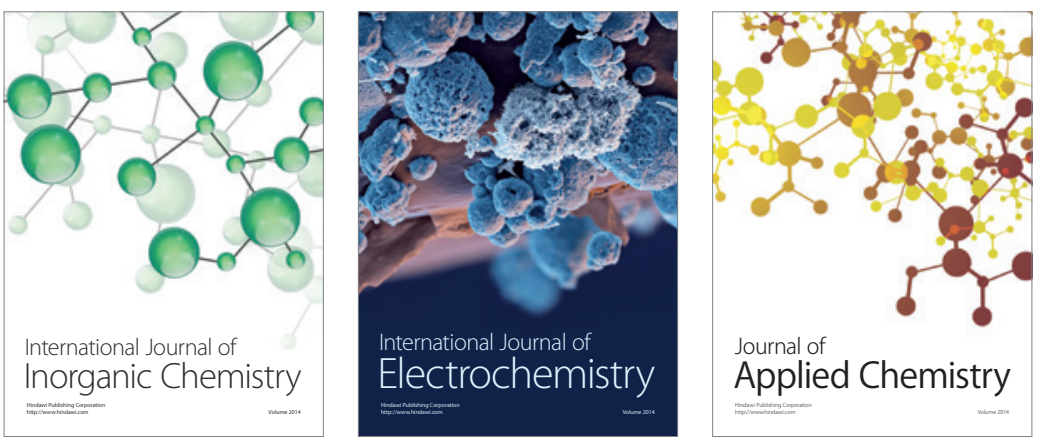

Journal of

Applied Chemistry
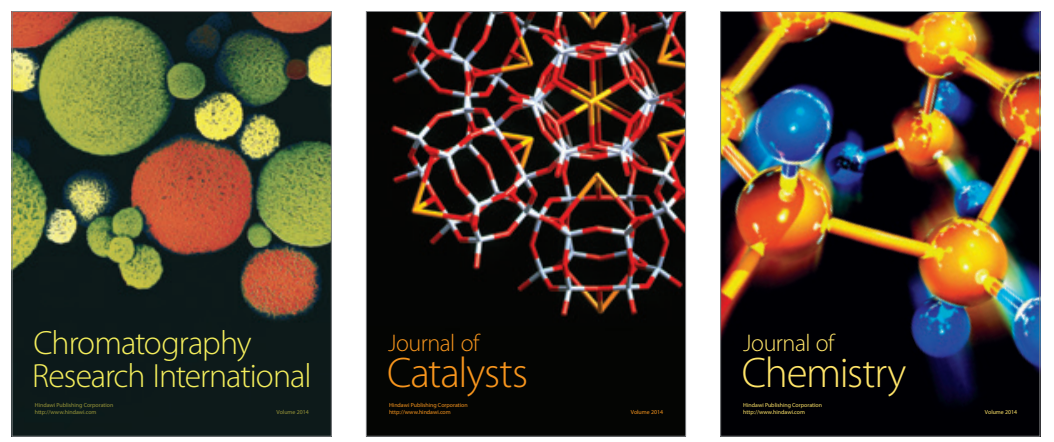
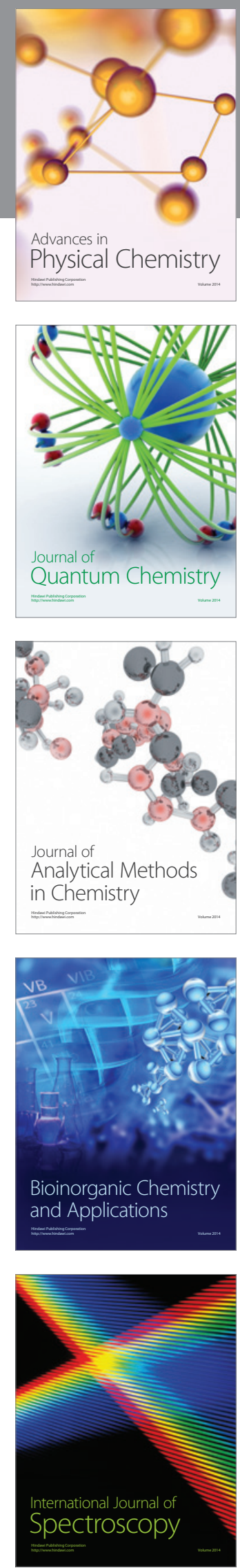